\title{
The FEBEX benchmark test: case definition and comparison of modelling approaches
}

\author{
E.E. Alonso ${ }^{\mathrm{a}, *}$, J. Alcoverro ${ }^{\mathrm{a}}$, F. Coste ${ }^{\mathrm{b}}$, L. Malinsky ${ }^{\mathrm{b}}$, V. Merrien-Soukatchoff ${ }^{\mathrm{c}}$,
} I. Kadiric, T. Nowak ${ }^{\mathrm{d}}$, H. Shao ${ }^{\mathrm{d}}$, T.S. Nguyen ${ }^{\mathrm{e}}$, A.P.S. Selvadurai ${ }^{\mathrm{e}, \mathrm{p}}$, G. Armand ${ }^{\mathrm{e}, \mathrm{p}}$, S.R. Sobolik ${ }^{\mathrm{f}}$, M. Itamura ${ }^{\mathrm{f}}$, C.M. Stone ${ }^{\mathrm{f}}$, S.W. Webb ${ }^{\mathrm{f}}$, A. Rejeb ${ }^{\mathrm{g}}$, M. Tijani ${ }^{\mathrm{h}}$, Z. Maouche ${ }^{\mathrm{h}}$, A. Kobayashi ${ }^{i}$, H. Kurikami ${ }^{j}$, A. Ito ${ }^{j}$, Y. Sugita ${ }^{j}$, M Chijimatsu $^{k}$, L. Börgesson ${ }^{1}$, J. Hernelind ${ }^{\mathrm{m}}$, J. Rutqvist ${ }^{\mathrm{n}}$, C.-F. Tsang ${ }^{\mathrm{n}}$, P. Jussila ${ }^{\mathrm{o}}$

\author{
a Department of Geotechnical Engineering and Geosciences, Universitat Politècnica de Catalunya, Edificio D-2, Campus Nord, \\ UPC 08034, Barcelona, Spain \\ ${ }^{\mathrm{b}}$ G3S-École Polytechnique, France \\ ${ }^{c}$ Laboratoire Environnement Géomécanique et Ouvrages, École des Mines de Nancy, France \\ ${ }^{\mathrm{d}}$ Federal Institute for Geosciences and Natural Resources, Germany \\ ${ }^{\mathrm{e}}$ Canadian Nuclear Safety Commission, Canada \\ ${ }^{\mathrm{f}}$ Sandia National Laboratories, USA \\ ${ }^{\mathrm{g}}$ IRSN, France \\ ${ }^{\mathrm{h}}$ École des Mines de Paris, France \\ ${ }^{\mathrm{i}}$ Kyoto University, Japan \\ ${ }^{\mathrm{j} J a p a n}$ Nuclear Cycle Development Institute, Japan \\ ${ }^{\mathrm{k}}$ Hazama Corporation, Japan \\ ${ }^{1}$ Clay Technology AB, Sweden \\ ${ }^{\mathrm{m}}$ FEM Tech $A B$, Sweden \\ ${ }^{\mathrm{n}}$ Lawrence Berkeley National Laboratory, USA \\ ${ }^{\circ}$ Helsinki University of Technology, Finland \\ ${ }^{\mathrm{p}}$ Mc Gill University, Canada
}

Accepted 2 March 2005

Available online 10 May 2005

\begin{abstract}
The FEBEX (Full-scale Engineered Barriers Experiment in Crystalline Host Rock) “in situ” test was installed at the Grimsel Test Site underground laboratory (Switzerland) and is a near-to-real scale simulation of the Spanish reference concept of deep geological storage in crystalline host rock. A modelling exercise, aimed at predicting field behaviour, was divided in three parts. In Part A, predictions for both the total water inflow to the tunnel as well as the water pressure changes induced by the boring of the tunnel were required. In Part B, predictions for local field variables, such as temperature, relative humidity, stresses and displacements at selected points in the bentonite barrier, and global variables, such as the total input power to the heaters were required. In Part C, predictions for temperature, stresses, water pressures and displacements in selected points of the host rock were required. Ten Modelling Teams from Europe, North America and Japan were involved in the analysis of the test. Differences among approaches may be found in the constitutive models used, in the simplifications made to the balance equations and in the geometric symmetries considered. Several aspects are addressed in the paper: the basic THM physical phenomena which dominate the test response are
\end{abstract}

\footnotetext{
${ }^{*}$ Corresponding author. Tel.: + $34934016866 ; 34934017256$; fax: + 34934017251.

E-mail address: eduardo.alonso@upc.es (E.E. Alonso).
} 
discussed, a comparison of different modelling results with actual measurements is presented and a discussion is given to explain the performance of the various predictions.

(C) 2005 Elsevier Ltd. All rights reserved.

Keywords: Benchmark; Case history; Nuclear waste; Bentonite; Thermo-hydro-mechanical analysis; Numerical analysis

\section{The FEBEX "In situ" test}

The Febex "in situ" test is currently in operation at the Grimsel Test Site, located in the granitic rocks of the Aare Massif in central Switzerland.

In order to perform the FEBEX "in situ" test, it was decided to excavate a new drift. Prior to it, two pilot boreholes (FEBEX 95.001 and FEBEX 95.002) were drilled in the area. Afterwards, the FEBEX drift was excavated between these pilot boreholes. It was parallel to FEBEX 95.002 borehole. Fig. 1 shows a perspective of the FEBEX drift and associated boreholes.

Borehole FEBEX 95.002, with a diameter of $86 \mathrm{~mm}$ and a length of $132.36 \mathrm{~m}$, was equipped with packers to isolate sections in which pore water pressures could be monitored.

During the period 25.09.95 to 30.10.95, the FEBEX drift was excavated using a TBM. The FEBEX drift has a diameter of $2.28 \pm 0.01 \mathrm{~m}$ and a total length of $71.4 \mathrm{~m}$.

Discrete flow measurements of water flow towards the excavated FEBEX tunnel were conducted in November 1995. Bulk inflow measurements were also performed in January 1996 using a flow gauge.

During the period 12.02 .96 to $04.04 .96,19$ in-drift boreholes (Ø 66 and $\varnothing 146 \mathrm{~mm}$ ) with a total length of $233 \mathrm{~m}$ were drilled from the test area of the FEBEX drift (tunnel meters $50-71 \mathrm{~m}$ ). Initially, the borehole layout was planned to be strictly radial. However, the boreholes were re-oriented in order to intersect the most relevant geological features (Fig. 1). These boreholes were initially used to conduct hydraulic tests and later to monitor several variables during the test (water pressure, temperature, stresses and displacements).

Extensive geological and hydraulic characterizations have been performed. Relevant documents are [1-4].

Shear zones are of considerable thickness in the area $(5-20 \mathrm{~m})$. At the intersection with tunnels, they display major outflows indicating their relevance as preferential flow paths. Lamprophyre dykes have also considerable dimensions (thickness in the order of several meters), although their relevance as preferential flow paths is not as important as shear zones. A common preferential flow path is the contact surface between the lamprophyre and the host rock. Fig. 2 provides a geological cross-section of the Grimsel area and shows the position of the FEBEX drift, bounded by two main shear zones.

The shear zones of high transmissivity constrain regional groundwater flow and therefore, they constitute natural hydro-geological boundaries of the FEBEX test area.

Hydraulic and Mechanical properties of granite and the Aare massif granite, in particular, have been reported by several authors [1,5-7]. Table 1 provides a set of significant parameters of intact Aare granite essentially based on core testing.

In a backanalysis of a ventilation experiment, the following expressions for the water retention curve and the relative permeability of the Grimsel granite were

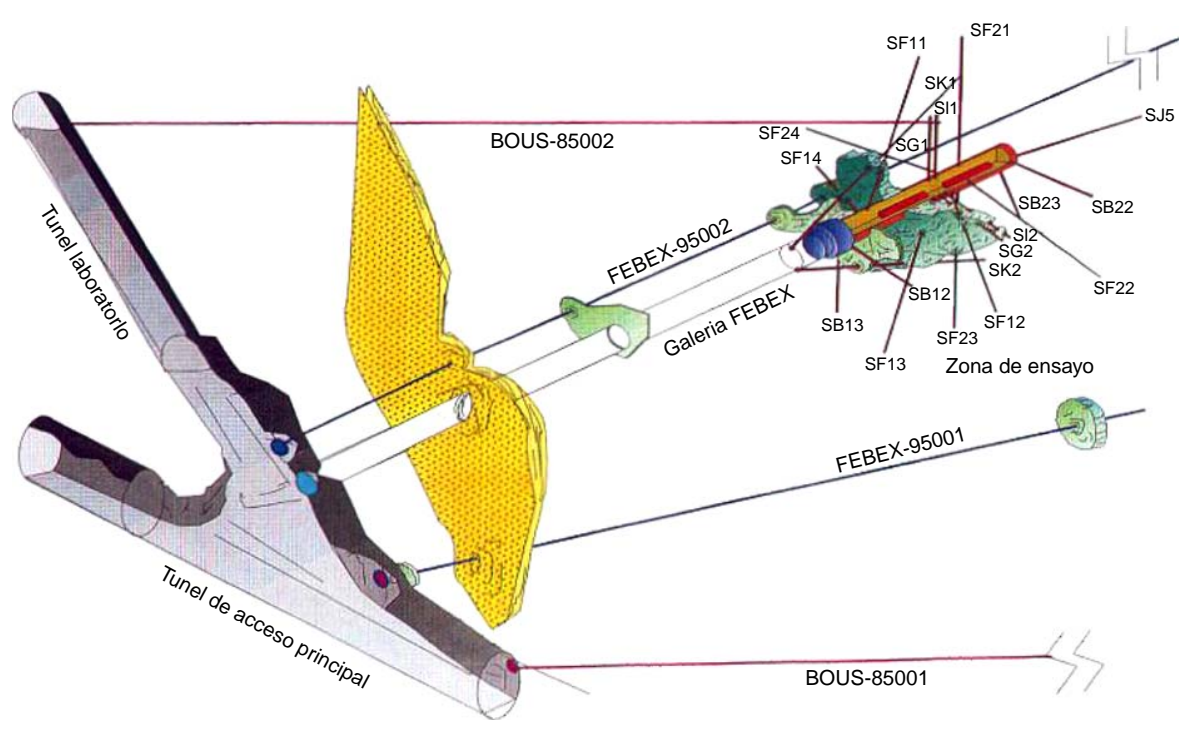

Fig. 1. Layout of FEBEX test and associated boreholes [2]. 


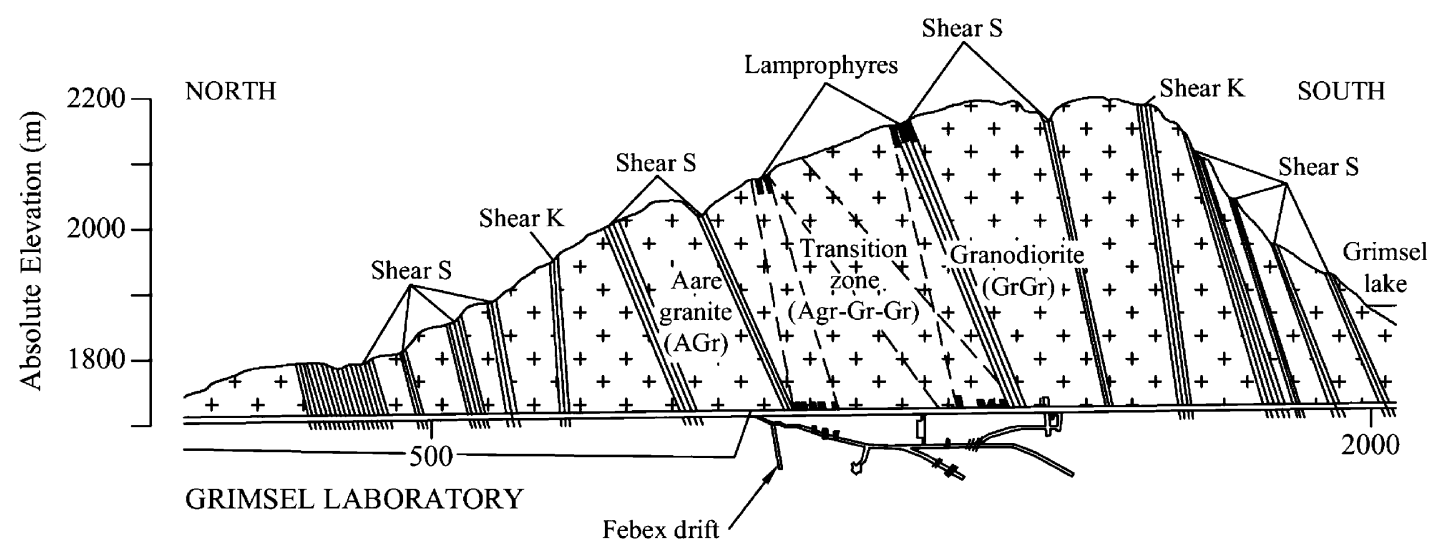

Fig. 2. Geological cross-section of the Grimsel area, simplified from [3].

Table 1

Parameters of intact granite at the Grimsel Test Site $[1,5]$

\begin{tabular}{lll}
\hline Parameter & Central Aare granite & Units \\
\hline Density & $2660 \pm 23.8$ & $\mathrm{~kg} / \mathrm{m}^{3}$ \\
Porosity & $0.4-1.0$ & $\mathrm{vol} \%$ \\
Uniaxial comp. strength & $169.1 \pm 37.1$ & $\mathrm{MPa}$ \\
Young's modulus E & $53.3 \pm 11.0$ & $\mathrm{GPa}$ \\
Poisson's ratio & $0.37 \pm 0.12$ & - \\
& $0.33 \pm 0.03$ & $\mathrm{MPa}$ \\
Tensile strength & $9.06 \pm 1.48$ & $\mathrm{MPa}$ \\
Triaxial comp. strength $\left(\sigma_{3} ; \sigma_{1}\right)$ & $5.0 ; 263.0 \pm 29.9$ & \\
& $10.0 ; 333.0 \pm 20.6$ & \\
& $20.0 ; 410.0 \pm 63.8$ & \\
Friction angle & 33 & $\mathrm{~m} / \mathrm{s}$ \\
p-wave vel. (specimen) & $3111 \pm 278$ & $\mathrm{~m} / \mathrm{s}$ \\
p-wave vel. (whole rock) & $5600 \pm 100$ & $\mathrm{~W} / \mathrm{m} \mathrm{K}$ \\
Therm. conductivity (wet) ${ }^{\mathrm{b}}$ & $3.34 \pm 0.35$ & $\mathrm{~W} / \mathrm{m} \mathrm{K}$ \\
Therm. conductivity $(\mathrm{dry})^{\mathrm{b}}$ & $2.58 \pm 0.19$ & $\mathrm{~m} / \mathrm{s}$ \\
Permeability & $5 \times 10^{-12}(10 \mathrm{MPa})$ & \\
& $3.5-4.5 \times 10^{-12}(5-15 \mathrm{MPa})$ & \\
& $5 \times 10^{-12}(5-30 \mathrm{MPa})$ & $\mathrm{K}-1$ \\
Coef. linear thermal expansion & $(5-12) \times 10^{-6}$ & $\mathrm{~K}{ }^{-1}$ \\
Coef. vol. thermal expansion & $(20-30) \times 10^{-6}$ & $\mathrm{~J} / \mathrm{kg} \mathrm{K}$ \\
Specific heat & $800-1250$ & \\
\hline
\end{tabular}

${ }^{\mathrm{a}}$ fractures;

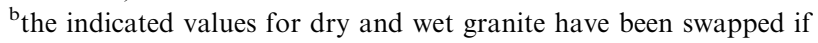
compared with the original reference, accepting that the thermal conductivity is larger for the wet material.

obtained [8]:

$s=1.74\left(S_{r}^{-1.68}-1\right)^{0.405}$,

$k_{r}=S_{r}^{0.5}\left[1-\left(1-S_{r}^{1.68}\right)^{0.595}\right]^{2}$,

where $s$ is the suction (in MPa), $S_{r}$ is the degree of saturation and $k_{r}$ is the relative permeability.

The vertical lithostatic stress at the level of the GTS test galleries is around 9-12 MPa. However, the horizontal stresses are substantially higher than the depth-related overburden pressure. Significant horizon- tal forces have been measured in the main compression direction NW-SE. Maximum and minimum horizontal stresses have been reported in the range $18 / 45 \mathrm{MPa}$ and $15 / 32 \mathrm{MPa}$. More details may be found in [6] and [7].

The "in situ" test consists of a near to full-scale simulation of a high level waste disposal facility, following the scheme shown in Fig. 3. Two electrical heaters, of dimensions and weight equivalent to those of a nuclear waste canister were placed in a $17.4 \mathrm{~m}$ long test section of the drift just described. The entire space surrounding the heaters was filled with blocks of compacted bentonite in order to complete the $17.4 \mathrm{~m}$ length of barrier for the test section. This test zone was isolated with a concrete plug.

Sensors (632) were installed to monitor the different thermo-hydro-mechanical processes that occur in both the clay barrier and the surrounding rock throughout the life of the test. A heating stage of more than 3 years was planned, followed by dismantling of the test. The present paper reports on the measurements recorded during the first 1000 days of operation.

Compacted bentonite blocks were manufactured by compacting statically in appropriate moulds a crushed bentonitic rock under vertical stresses of 40-45 MPa. The average values of water content and dry density of all the manufactured blocks were $14.4 \%$ (by weight) and $1.69 \mathrm{~g} / \mathrm{cm}^{3}$, respectively.

Fig. 4 shows a view of the test during the process of installation. Heaters were located inside a perforated steel liner as shown in the figure. A typical cross-section of the test showing the relevant dimensions is shown in Fig. 5.

Sensors located inside the barrier were arranged in the cross-sections shown in Fig. 6. Cables were carried radially to outer grooves in the bentonite and taken eventually, through the concrete plug, to the service area of the tunnel. 


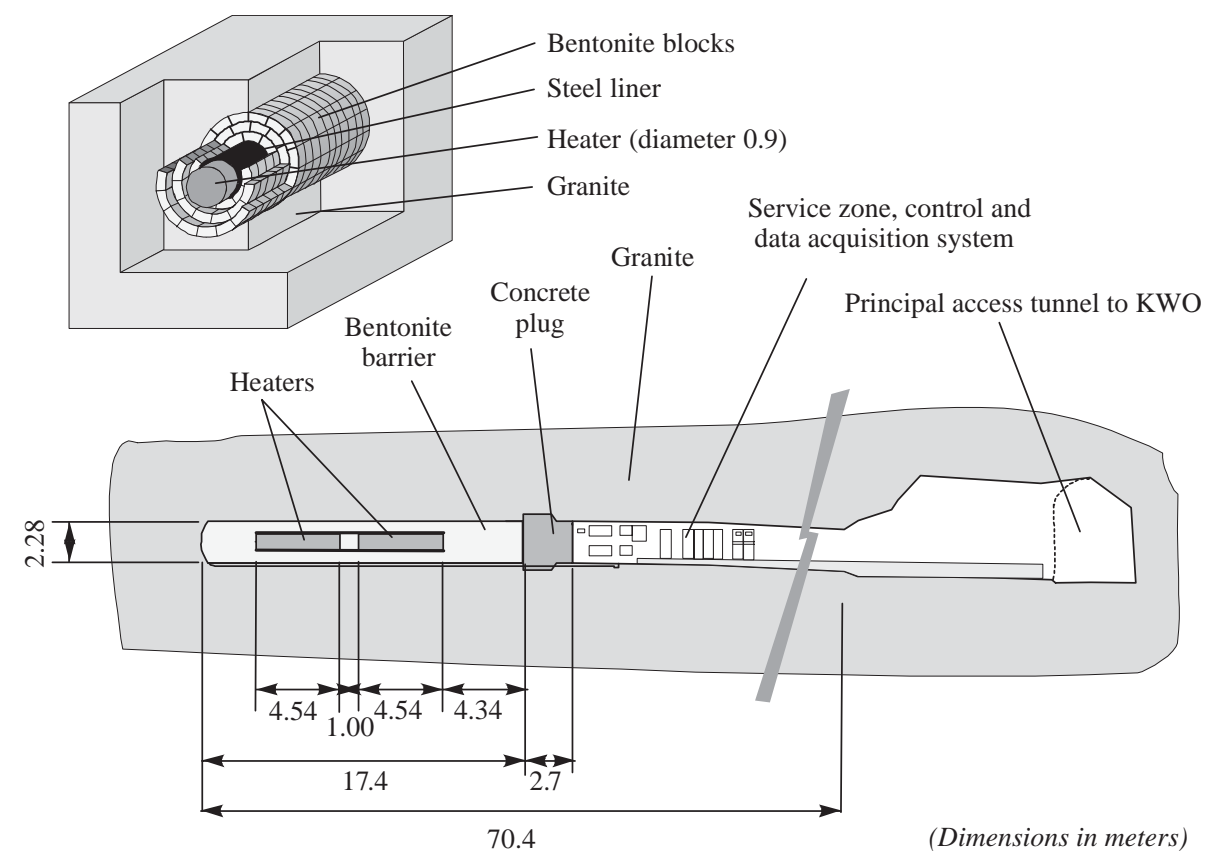

Fig. 3. General scheme of the FEBEX "in situ" test.

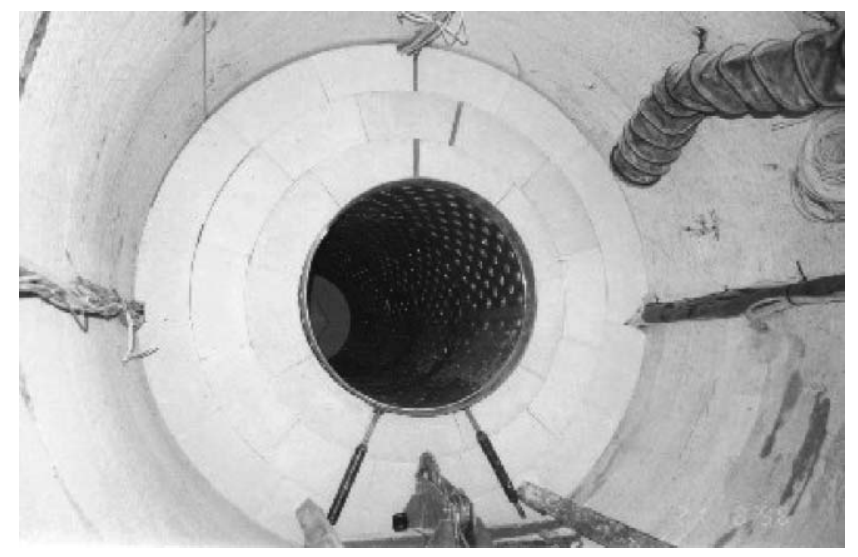

Fig. 4. A view of FEBEX test construction.

A total volume of gaps of $5.53 \%$ of the emplacement volume was measured. Therefore, the average dry density of the barrier was established as $1.60 \mathrm{~g} / \mathrm{cm}^{3}$. Typically, the dry density varied by $\pm 0.25 \mathrm{~g} / \mathrm{cm}^{3}$ among the different slices of assembled blocks.

Heating started on February 27, 1997 a date identified as "day 0 " on the time scale. The sequence of initiation was as follows:

- During an initial period of 20 days a constant power of $1200 \mathrm{~W}$ per heater was applied.

- Over the next 33 days the power was increased to $2000 \mathrm{~W}$ per heater and it was maintained constant to approximate the temperature of $100{ }^{\circ} \mathrm{C}$ desired at the surface of the steel liner.
- Finally, on 21st April 1997 (day 53) the system was switched to the constant temperature control mode. The necessary electric power was adjusted to maintain $100^{\circ} \mathrm{C}$ at the hottest control point located at the canister-bentonite contact.

\subsection{The FEBEX bentonite}

The properties of FEBEX bentonite have been extensively investigated over the past 8 years. Several recent publications describe the thermo-hydro-mechanical properties of the compacted material [9-17]. Extensive information is also available for the bentonite "S-2", a material of essentially the same origin (a quarry in Serrata de Níjar, Almería, Spain) as the FEBEX one. A summary of relevant properties, taken from some of the mentioned references, is given here.

The conditioning of the bentonite in the quarry, and later in the manufacturing factory, was strictly mechanical (homogenization, rock fragment removal, drying, crumbling of clods, and sieving) and aimed at obtaining a granulated material with the specified characteristics of grain-size distribution and water content: Fraction of particles of more than $5 \mathrm{~mm}$ less than $5 \%$, and fraction of particles smaller than $74 \mu \mathrm{m}$ greater than $85 \%$; water content, after conditioning, between $12.5 \%$ and $15.5 \%$ in weight. Table 2 provides a set of identification parameters as determined by two laboratories: CIEMAT and UPC.

Swelling pressure tests were performed using conventional oedometers on samples saturated with distilled water. A regression curve was developed for the swelling 


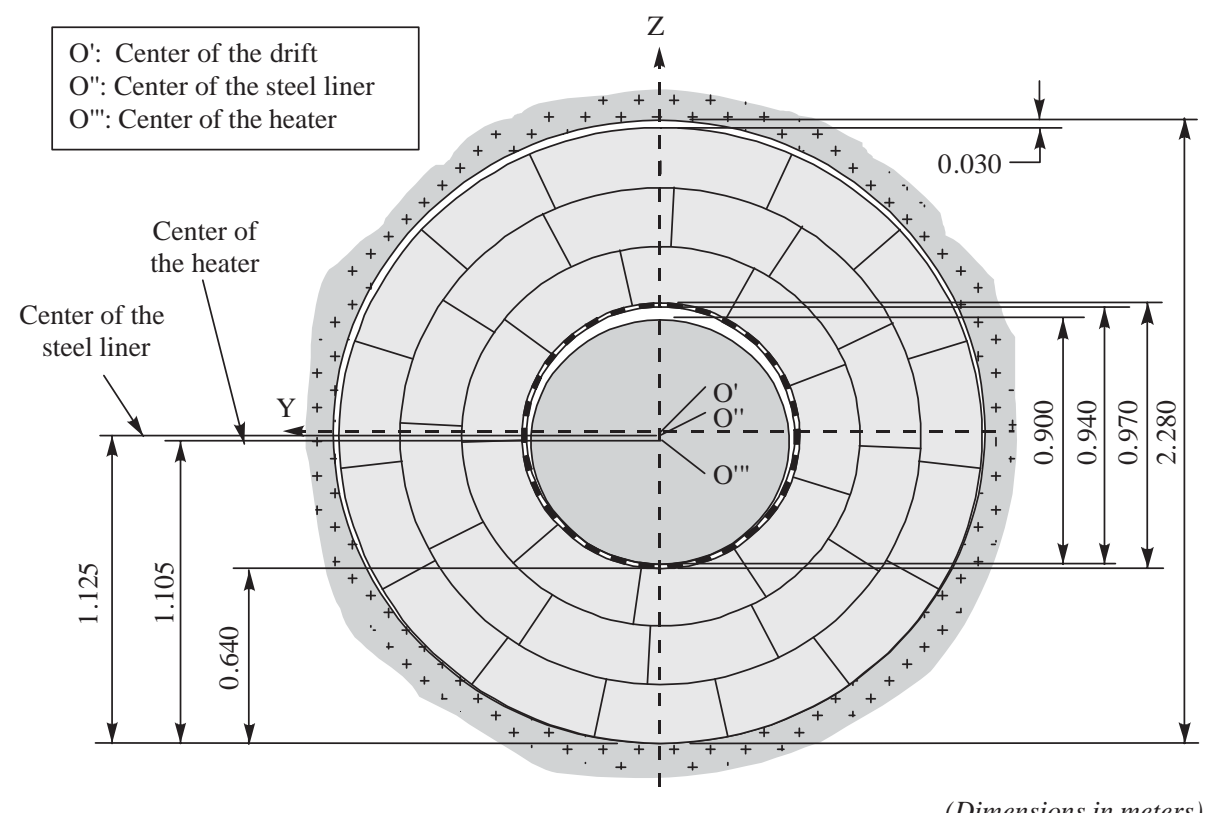

Fig. 5. Typical cross-section of the clay barrier.

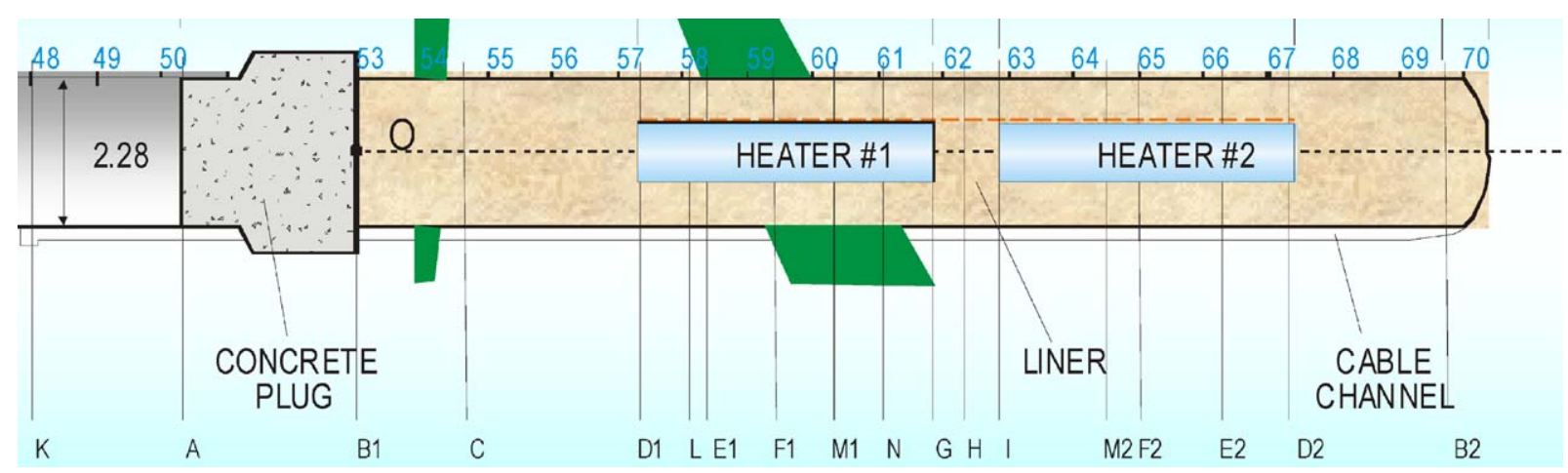

Fig. 6. Arrangement of instrumented sections.

pressure of the FEBEX bentonite, as shown on Fig. 7 (solid line), and it is expressed by the equation

$P_{\mathrm{s}}=\exp \left(6.77 \rho_{\mathrm{d}}-9.07\right)$,

where $P_{\mathrm{s}}$ is the swelling pressure in $\mathrm{MPa}$ and $\rho_{\mathrm{d}}$ is the dry density in $\mathrm{g} / \mathrm{cm}^{3}$.

A series of swelling under load tests, performed in oedometer tests, provided additional information on the expansivity and mechanical behaviour of the material. The following equation provides a relationship between 1D swelling strain upon saturation, $\varepsilon$, applied vertical confining stress, $\sigma(\mathrm{MPa})$ and dry density $\rho_{\mathrm{d}}\left(\mathrm{g} / \mathrm{cm}^{3}\right)$ :

$\varepsilon=-46.9-19.4 \log \sigma+36.6 \rho_{\mathrm{d}}$.
Table 2

Identification properties of FEBEX bentonite

\begin{tabular}{lcl}
\hline Property & CIEMAT & UPC-DIT \\
\hline $\begin{array}{l}\text { Water content in equilibrium with } \\
\text { the air in the laboratory, in \% }\end{array}$ & $13.7 \pm 1.3$ & $13.3 \pm 1.3$ \\
Liquid limit, in \% & $102 \pm 4$ & $93 \pm 1$ \\
Plastic limit, in \% & $53 \pm 3$ & $47 \pm 2$ \\
Plasticity index & $49 \pm 4$ & $46 \pm 2$ \\
Specific weight & $2.70 \pm 0.04$ & - \\
Grain-size distribution, in \% & & \\
Fraction less than $74 \mu \mathrm{m}$, in \% & $92 \pm 1$ & 87 \\
Fraction less than $2 \mu \mathrm{m}$, in \% & $68 \pm 2$ & 45 \\
Specific surface, in $\mathrm{m}^{2} / \mathrm{g}$ & & \\
Total & $725 \pm 47$ & - \\
External, BET & $32 \pm 3$ & - \\
\hline
\end{tabular}


Many determinations of saturated hydraulic conductivity are available. Some of them are collected in Fig. 8.

Infiltration tests were also performed to determine the relative permeability. It was found that the relationship

$k_{r}=S_{r}^{n}$,

where " $n$ " is a parameter determined to fit experimental data and $S_{r}$ is the degree of saturation. A reference value for $n$ is 3 although a significant variability was found.

Water retention curves were determined under free and constant volume conditions. The latter are more precise. Curves relating suction and degree of saturation for wetting-drying paths at different constant dry

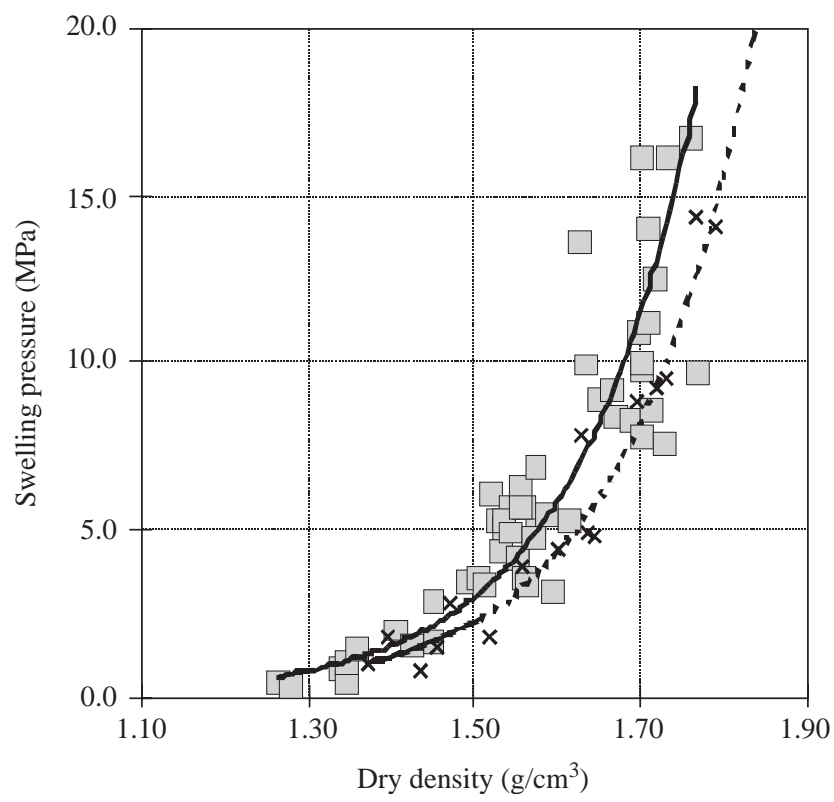

Fig. 7. Swelling pressure of FEBEX bentonite (square dots). Crosses correspond to the "S-2" bentonite [9]. densities are shown in Fig. 9. It was found that the concept of a constant intrinsic permeability does not hold, even approximately, for an expansive material such as the FEBEX bentonite. Fig. 10 shows values of "intrinsic" permeability determined in gas and water flow experiments. Extremely large differences were found, due to the change in microstructure of the compacted material when its water content changes.

Thermal properties are also available. Specific heat has been determined for bentonite S-2. The relationship between specific heat and temperature fits the following equation, in a range of temperatures

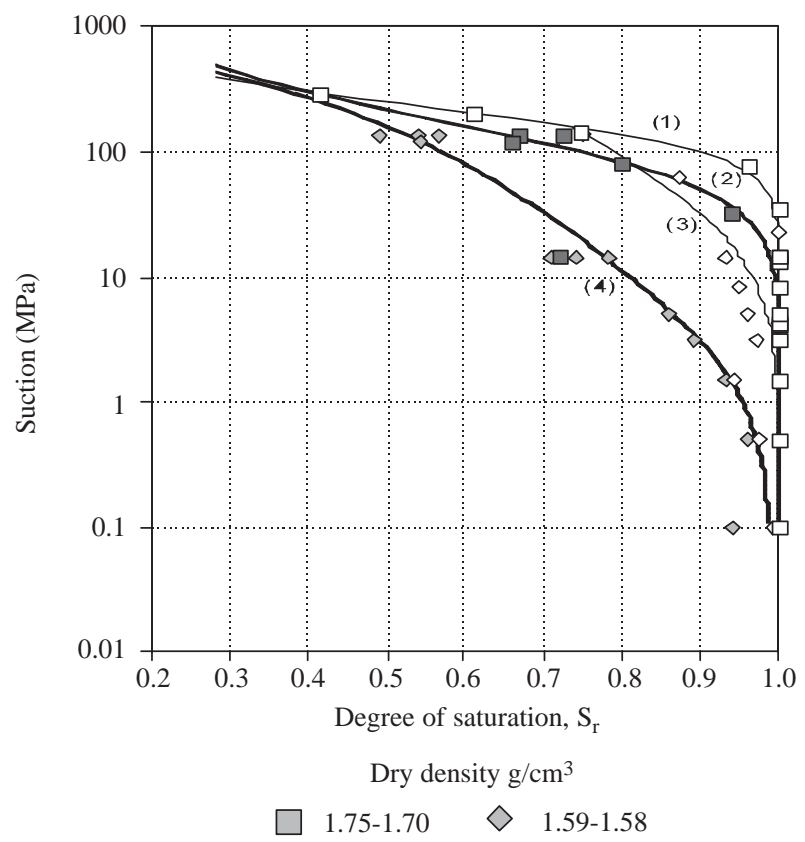

Fig. 9. Water retention characteristics of FEBEX bentonite. Bold symbols correspond to wetting paths [14].

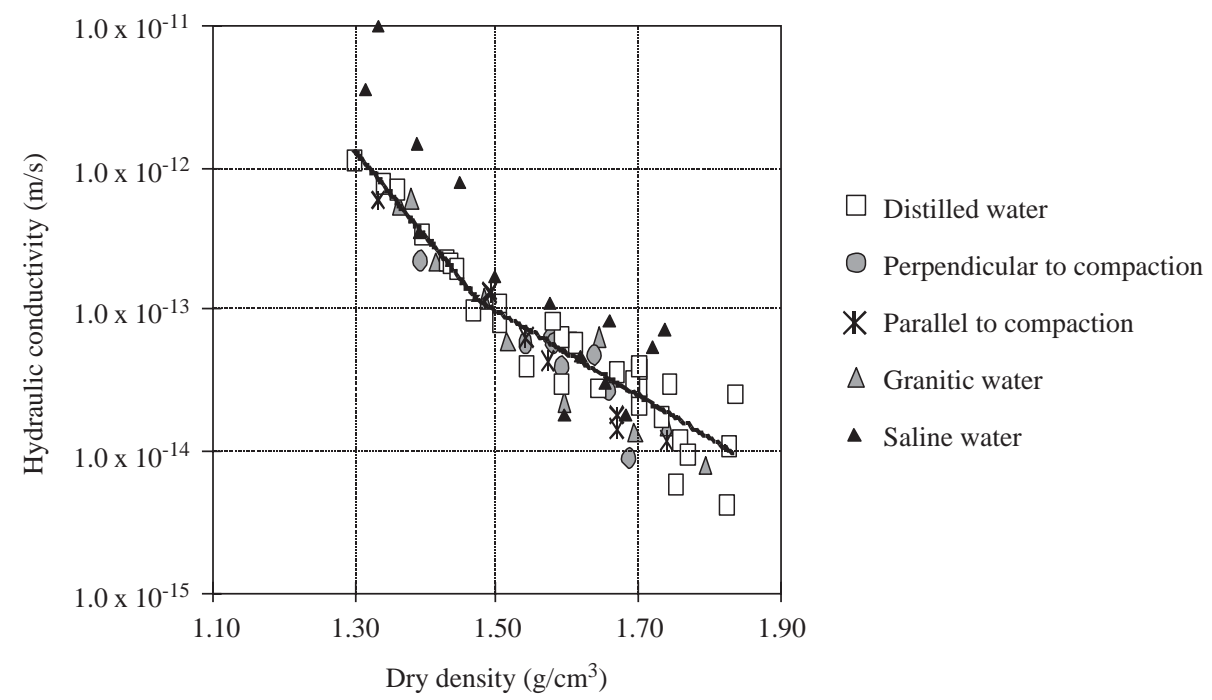

Fig. 8. Saturated hydraulic conductivity as a function of dry density of FEBEX bentonite [9]. 


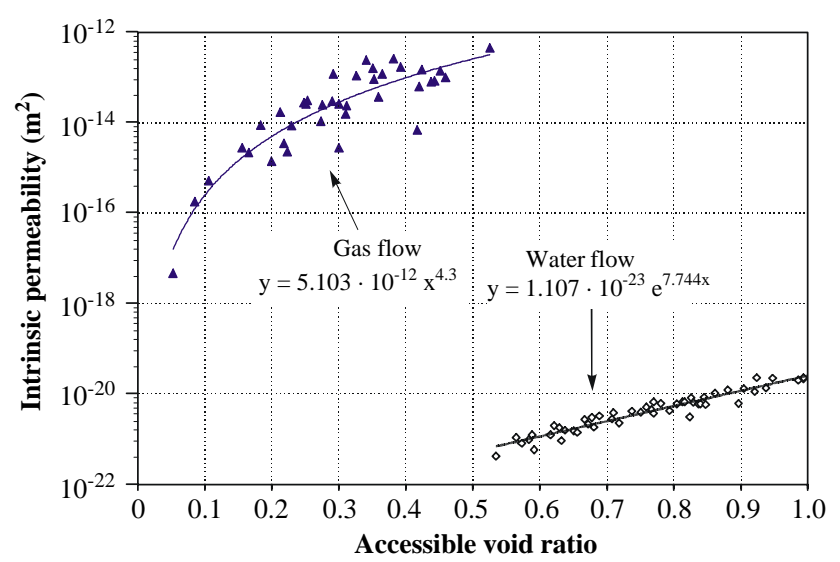

Fig. 10. Intrinsic permeability of the compacted clay obtained from saturated water flow and from unsaturated gas flow tests. In gas flow tests, the accessible void ratio indicates the ratio between gas accessible pore volume and particle volume $\left(\mathrm{e}\left(1-S_{r}\right)\right)[10]$.
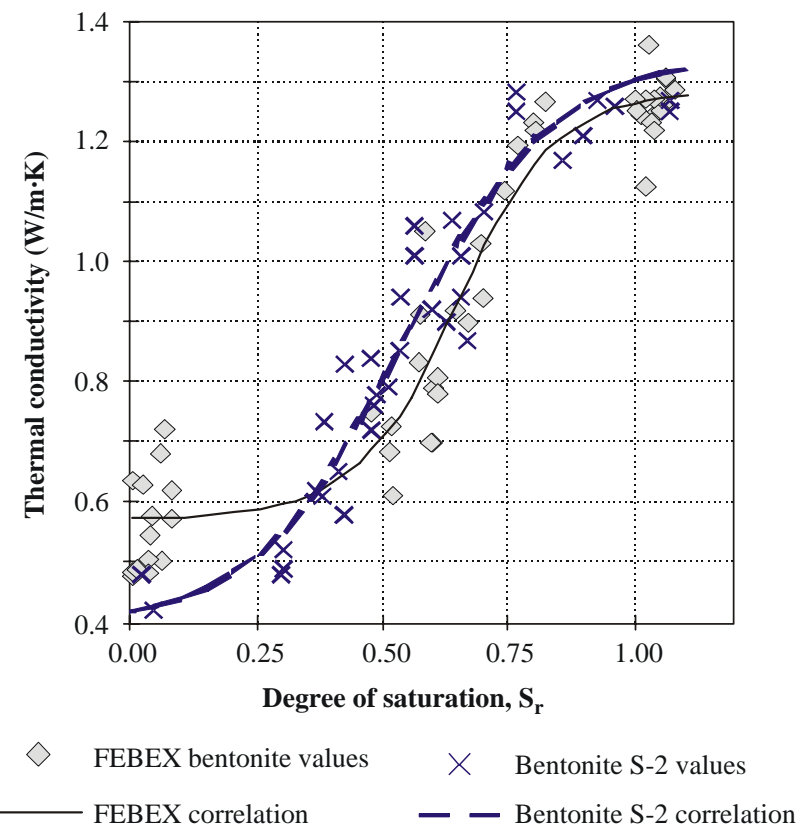

Fig. 11. Thermal conductivity as a function of degree of saturation [14].

between 45 and $150{ }^{\circ} \mathrm{C}$ :

$c_{\mathrm{s}}=1.38 \cdot T+732.5$,

where $c_{\mathrm{s}}$ is the specific heat, in $\mathrm{J} / \mathrm{kg}^{\circ} \mathrm{C}$, and $T$ is the temperature, in ${ }^{\circ} \mathrm{C}$. Measured thermal conductivities are given in Fig. 11, as a function of degree of saturation.

Measured thermal expansions for heating and cooling paths are given in Fig. 12.

More sophisticated suction controlled tests which explore the behaviour of the bentonite under specific stress and suction paths are described in the references given above. Tests on small scale cells involving simultaneous hydration and heating were also performed. They are boundary value problems and their analysis may provide a refined evaluation of constitutive parameters. Some of the research groups participating in the FEBEX benchmark test have used this information to their advantage. Their analyses are published elsewhere.

\section{The benchmark}

The benchmark was divided into three parts, described as follows in general terms:

Part A: Hydro-mechanical modelling of the rock.

Based on the available geological, hydraulic and mechanical characterizations of the site as well as on results of hydraulic tests performed in boreholes, a hydro-mechanical model for the zone around the FEBEX tunnel was to be prepared. Using this model, changes in water pressure induced by the boring of the FEBEX tunnel in the near vicinity, as well as the total water flow rate to the excavated tunnel were required.

Part B: Thermo-hydro-mechanical analysis of the bentonite behaviour.

Based on the characterization of the bentonite and on the details of the process of test installation, a thermohydro-mechanical model for the bentonite barrier and the heaters was to be prepared. Using this model, the thermo-hydro-mechanical response of the bentonite barrier as a result of the heat released by the heaters and the hydration from the host rock was required. Local field variables such as temperature, relative humidity, stresses and displacements, as well as global variables such as total input power to the heaters were required.

Part C: Thermo-hydro-mechanical analysis of the rock.

Based on the characterization of the rock massif and on the details of the process of test installation and performance, the rock response in the immediate vicinity of the buffer was required. The rock is now subjected to the heat released by heaters and to swelling pressures resulting from bentonite hydration. The initial hydrological regime (Part A) is also modified by the presence of the impervious barrier. Temperature, stresses, water pressures and displacements in selected points of the rock were required.

A maximum number of 10 Modelling Teams have participated in the different benchmark activities related to the FEBEX test. Their names, codes and symbols used in the presentation of results are given in Table 3.

Details on the modelling approaches used by the different participants in the Benchmark are described in companion papers in this issue. The performance of the 


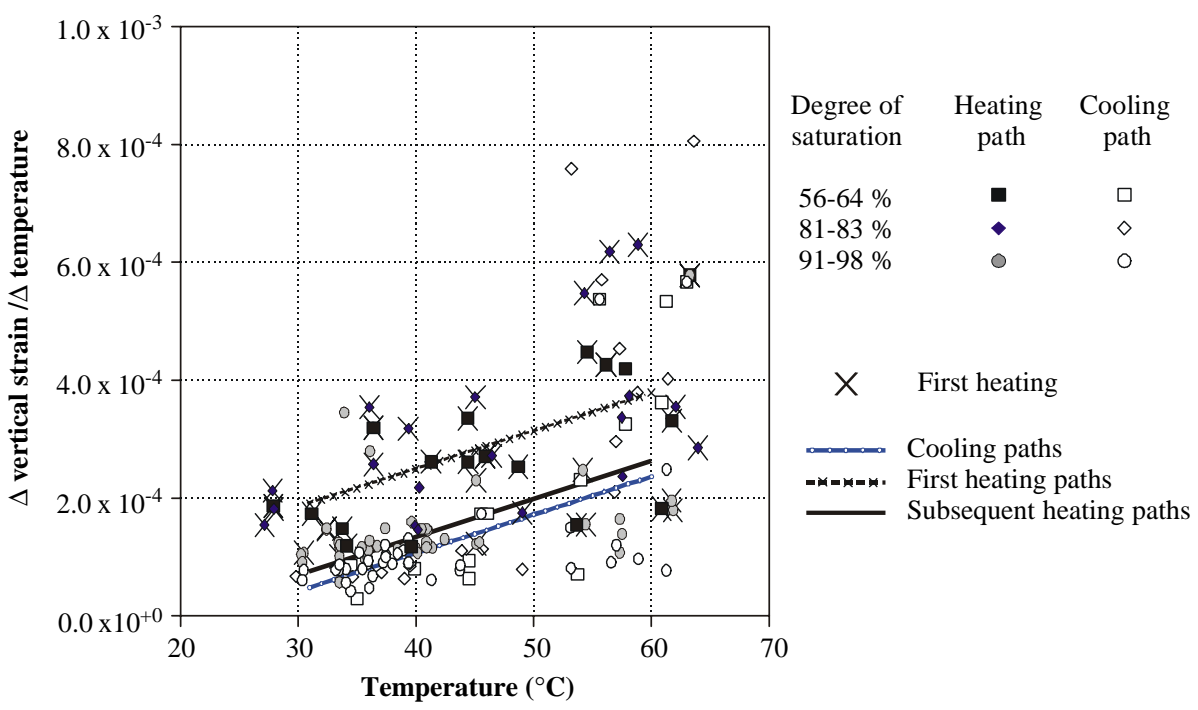

Fig. 12. Linear thermal expansion as a function of temperature [14].

Table 3

Codes, symbols and colours assigned to participants and co-ordinator

\begin{tabular}{|c|c|c|c|c|}
\hline Funding Organisation & Modelling Team/Coordinator & Code & Symbol & Color \\
\hline $\begin{array}{l}\text { National Radioactive Waste Management Agency } \\
\text { (ANDRA) }\end{array}$ & $\begin{array}{l}\text { - Laboratory "Sols, Solides, Structures" Grenoble. } \\
\text { École Polytechnique }\end{array}$ & ANG & & Red \\
\hline $\begin{array}{l}\text { National Radioactive Waste Management Agency } \\
\text { (ANDRA) }\end{array}$ & $\begin{array}{l}\text { - Laboratoire Environnement, Géomécanique et } \\
\text { Ouvrages. Ecole des Mines de Nancy }\end{array}$ & ANN & & Red \\
\hline $\begin{array}{l}\text { Federal Institute for Geosciences and Natural } \\
\text { Resources (BGR) }\end{array}$ & $\begin{array}{l}\text { - Federal Institute for Geosciences and Natural } \\
\text { Resources }\end{array}$ & BGR & & Green \\
\hline Canadian Nuclear Safety Commission (CNSC) & $\begin{array}{l}\text { - Canadian Nuclear Safety Commission } \\
\text { - McGill University }\end{array}$ & CNS & $\diamond$ & Green \\
\hline U.S. Department of Energy (DOE) & - Sandia National Laboratories & DOE & & Blue \\
\hline $\begin{array}{l}\text { Institute for Radiological Protection and Nuclear } \\
\text { Safety (IRSN) }\end{array}$ & $\begin{array}{l}\text { - Institute for Radiological Protection and Nuclear } \\
\text { Safety } \\
\text { - Ecole des Mines de Paris }\end{array}$ & IPS & $\Delta$ & Blue \\
\hline Japan Nuclear Cycle Development Institute (JNC) & $\begin{array}{l}\text { - Hazama Corporation } \\
\text { - Kyoto University } \\
\text { - Japan Nuclear Cycle Development Institute }\end{array}$ & $\mathrm{JNC}$ & $\mathbf{X}$ & Brown \\
\hline $\begin{array}{l}\text { Swedish Nuclear Fuel and Waste Management Co } \\
\text { (SKB) }\end{array}$ & $\begin{array}{l}\text { - Clay Technology AB } \\
\text { - FEM-Tech AB }\end{array}$ & SKB & & Black \\
\hline Swedish Nuclear Power Inspectorate (SKI) & - Lawrence Berkeley National Laboratory & SKI & & Black \\
\hline $\begin{array}{l}\text { Radiation and Nuclear Safety Authority of Finland } \\
\text { (STUK) }\end{array}$ & - Helsinki University of Technology & STU & & Orange \\
\hline $\begin{array}{l}\text { Empresa Nacional de Residuos Radiactivos SA } \\
\text { (ENRESA) }\end{array}$ & - Technical University of Catalonia (Coordinator) & UPC & 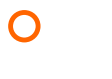 & Orange \\
\hline
\end{tabular}

test and a comparison of calculated and most significant measured variables are described in the next three sections. The Benchmark was conceived as a blind prediction exercise although additional calculations and analyses were made once the field data was released. The graphs presented include the final calculations submitted 
by different teams. Reference is made, when appropriate, to a true "blind" prediction.

\section{Part A: Hydro-mechanical modelling of the rock}

\section{Introduction}

Some of the observations made during the excavation of the tunnel and immediately afterwards provided an interesting large scale experiment of a hydro-mechanical nature. Two types of measurements have been selected to develop the modelling exercise: the actual water inflow rates into the FEBEX tunnel and the water pressure response in the vicinity of the tunnel outer perimeter as a consequence of the tunnel excavation by the TBM.

Flow measurements into the open tunnel provided an integrated variable, controlled by the problem geometry, rock mass fracture pattern, fracture anisotropy, rock permeability and boundary conditions. The hydrogeological characterization carried out $[3,4]$ reveals that the rock mass surrounding the FEBEX tunnel has a rather involved distribution of cracks. This zone was explored by a number of instrumented boreholes, in which hydro-geological tests were carried out. The surface of the test zone of the FEBEX tunnel was carefully mapped. A hydro-geological model, in which several important fractures were specifically considered, whereas the rest were included in an equivalent continuum, has been described in $[3,4]$. The flow through fractures was found to be of the same order of magnitude as the flow through the rock matrix (Fig. 14).
The second part of the exercise asked for a prediction of the transient changes in water pressure recorded at two borehole intervals in the close proximity of the advancing tunnel. Fig. 13 is a Plan view of the Febex tunnel and the Borehole FEBEX 95.002 where observations were made in the intervals $\mathrm{P} 3$ and $\mathrm{P} 4$.

As the excavation of the FEBEX tunnel was taking place, a consistent relation between water pressure variations and TBM activity was observed in some packed-off segments of borehole FEBEX 95.002. They are shown in Fig. 15 where measured pore pressures correspond to the acronym "UPC". During periods of TBM activity water pressure increased, whereas in periods of inactivity water pressure decreased.

The rate of the tunnel drilling and the permeability determine both the rate of increase and decrease of pore water and, consequently, the magnitude of the pressure peak. Whereas in one interval (P4) a marked pore water pressure variation was recorded, in a neighbouring interval (P3) this variation was much smaller, a fact attributed to the presence of a pervious fracture connecting the measuring interval and the tunnel. Only the behaviour in $\mathrm{P} 4$ and associated predictions have been included in Fig. 15.

\section{Modelling approaches for Part A}

In the zone surrounding the FEBEX tunnel it is possible to identify macroscale features at a scale comparable to the scale of the problem, such as lamprophyre dykes and shear zones, and microscale features at a scale smaller than the scale of the problem, such as secondary fractures and microfractures.

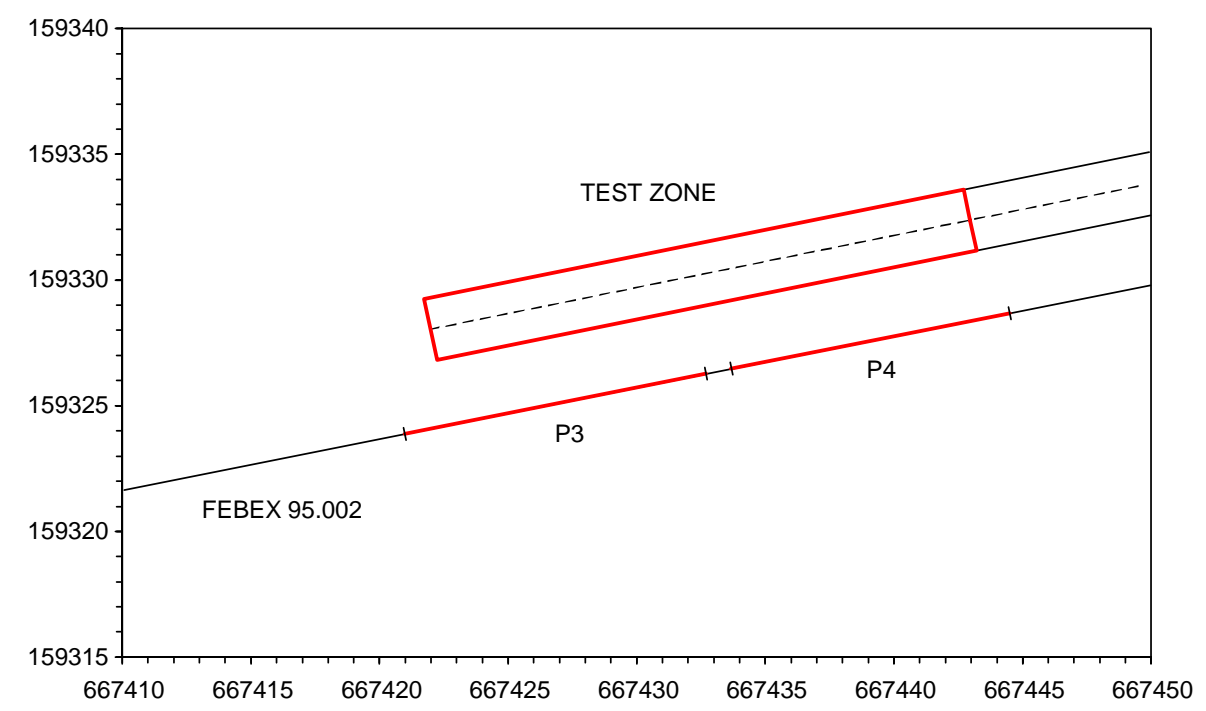

Fig. 13. Plan view of the test zone of the FEBEX drift and the borehole FEBEX 95.002, showing the intervals P3 and P4. Grimsel Test Site coordinates (in $\mathrm{m}$ ) are used (north is parallel to the $y$-axis). 
In order to model the macroscale features, two types of approaches have been used:

- equivalent 3D continuum (CNS, DOE, IPS, JNC, SKB, SKI),

- equivalent 2D continuum (ANG, ANN).

All modelling teams approximate the microscale features (porosity, fissures, microfractures) by means of a 3D continuum. However, some Modelling Teams (DOE and JNC) have established a hydraulic and mechanical link with microscale features by taking into account the opening of joints in their 3D equivalent continua, while others (ANN) have not included any hydraulic link with microscale features and they considered their equivalent continua to be impervious. As shown in Table 4, the macroscale features that have been taken into account in the model vary among the Modelling Teams.

Another aspect of the modelling work is the size of the zone to be included into the model. Essentially, two different mesh sizes have been used:

- tens of meters (ANG, CNS, DOE, JNC),

- hundreds of meters (ANN, IPS, SKB, SKI).

Only ANN and SKB extended their meshes to reach hydrological natural boundaries, such as the access tunnel to the Grimsel Test Site or the shear zones.

Some Modelling Teams (CNS, IPS and SKB) used a simplified model (taking into account only water flow) in order to determine the total water inflow to the tunnel and a more complete model (taking into account water flow and mechanical deformation) in order to determine the water pressure response to the tunnel excavation. The rest of Modelling Teams used the same model (taking into account water flow and mechanical deformation) for both calculations. Table 5 summarizes

Table 4

Macroscale features taken into account by modelling teams

\begin{tabular}{ll}
\hline Team & Remarks \\
\hline ANG & $\begin{array}{l}\text { Rock mass with anisotropic permeability and 2 } \\
\text { discrete fractures }\end{array}$ \\
ANN & Rock mass and 12 discrete fractures \\
CNS & $\begin{array}{l}\text { Rock mass, 2 lamprophyres and } 3 \text { fracture zones } \\
\text { and 2 lamprophyres }\end{array}$ \\
DOE & Rock mass \\
IPS & Rock mass, lamprophyre and a heterogeneous \\
JNC & hydraulic conductivity \\
SKB & Rock mass, 3 shear zones and 2 lamprophyres \\
SKI & Rock mass, near field rock, local fracture zone, \\
& lamprophyre
\end{tabular}

Table 5

Physical phenomena and couplings considered

\begin{tabular}{llll}
\hline Team & $\begin{array}{l}\text { Water } \\
\text { inflow }\end{array}$ & $\begin{array}{l}\text { Pressure } \\
\text { response }\end{array}$ & Remarks \\
\hline ANG & $\mathrm{M} \leftrightarrow \mathrm{H}$ & $\mathrm{M} \leftrightarrow \mathrm{H}$ & $\begin{array}{l}\text { 2D fractures are rigid } \\
\text { Water flows only } \\
\text { through fractures }\end{array}$ \\
ANN & $\mathrm{M} \rightarrow \mathrm{H}$ & $\mathrm{M} \rightarrow \mathrm{H}$ & $\mathrm{M} \leftrightarrow \mathrm{H}$ \\
CNS & $\mathrm{H}$ & $\mathrm{M} \rightarrow \mathrm{H}$ & $\begin{array}{l}\text { Joint aperture taken } \\
\text { into account }\end{array}$ \\
IPS & $\mathrm{M} \rightarrow \mathrm{H}$ & $\mathrm{M} \leftrightarrow \mathrm{H}$ & Joint aperture taken \\
JNC & $\mathrm{M} \leftrightarrow \mathrm{H}$ & $\mathrm{M} \leftrightarrow \mathrm{H}$ & into account \\
SKB & $\mathrm{H}$ & $\mathrm{M} \leftrightarrow \mathrm{H}$ & \\
SKI & $\mathrm{M} \leftrightarrow \mathrm{H}$ & $\mathrm{M} \leftrightarrow \mathrm{H}$ & \\
\hline
\end{tabular}

$\mathrm{M}=$ mechanical deformation, $\mathrm{H}=$ water flow.

the physical phenomena and the couplings between them considered by the various Modelling Teams. Although a unique model for both predictions was requested, the use of a simplified model (taking into account only water flow) for the prediction of the total water inflow to the test zone indicates that some Modelling Teams considered "a priori" that the influence of the mechanical deformation on water flow was negligible.

\section{Comparison of field data with model calculations for Part A}

Total water inflow in the test zone (which extends along $17.40 \mathrm{~m}$ along tunnel axis, from coordinates 54.00-71.40) was measured by two techniques (absorbing pads on selected points of the tunnel wall and a small gauge measuring overall leaked water) at different dates in the period January-May 1996, once the tunnel was fully excavated.

The first technique involved discrete measurements at selected points on the FEBEX tunnel by means of absorbing pads. The absorbing pads were weighted before and after their placement in order to determine the volume of leaked water. The surface of the test zone of the FEBEX tunnel was divided into three types of zones: (1) the granite matrix, (2) fracture zones and (3) well-defined water inflow points.

According to the water inflow, a rank was also assigned to these zones: ranks 0 and 1 to the matrix, ranks 2, 3 and 4 to the fractures and ranks 5 and 6 to the well-identified points. Table 6 shows the water inflow assigned to each rank, indicating in each case the reference used to measure it. With this information, it was possible to know the distribution of water input flow on the wall of the FEBEX tunnel (Fig. 14, taken from [2]). 
Table 6

Assignment of water inflows to ranks, and computation of the various components of the total water inflow (F. Ortuño, personal communication)

\begin{tabular}{lllll}
\hline Rank & Specific water inflow & Reference used & Area, length or points & Total water inflow \\
\hline 0 & $3.0 \times 10^{-10} \mathrm{~m}^{3} / \mathrm{s}^{2}$ & Point B FEBEX tunnel & $75 \mathrm{~m}^{2}$ & $2.25 \times 10^{-8} \mathrm{~m}^{3} / \mathrm{s}$ \\
1 & $7.0 \times 10^{-10} \mathrm{~m}^{3} / \mathrm{s} / \mathrm{m}^{2}$ & L490 ventilation tunnel & $18 \mathrm{~m}^{2}$ & $1.26 \times 10^{-8} \mathrm{~m}^{3} / \mathrm{s}$ \\
2 & $1.5 \times 10^{-9} \mathrm{~m}^{3} / \mathrm{s} / \mathrm{m}$ & Average of ranks 1 and 3 & $6.21 \mathrm{~m}$ & $9.31 \times 10^{-9} \mathrm{~m}^{3} / \mathrm{s}$ \\
3 & $3.0 \times 10^{-9} \mathrm{~m}^{3} / \mathrm{s} / \mathrm{m}$ & Point A FEBEX tunnel & $3.62 \mathrm{~m}$ & $1.09 \times 10^{-8} \mathrm{~m}^{3} / \mathrm{s}$ \\
4 & $5.0 \times 10^{-9} \mathrm{~m}^{3} / \mathrm{s} / \mathrm{m}$ & Points C, D FEBEX tunnel & $1.54 \mathrm{~m}$ & $7.69 \times 10^{-9} \mathrm{~m}^{3} / \mathrm{s}$ \\
5 & $1.0 \times 10^{-8} \mathrm{~m}^{3} / \mathrm{s}$ & Measured & 5 points & $5.00 \times 10^{-8} \mathrm{~m}^{3} / \mathrm{s}$ \\
6 & $1.7 \times 10^{-8} \mathrm{~m}^{3} / \mathrm{s}$ & Measured & 1 point & $1.67 \times 10^{-8} \mathrm{~m}^{3} / \mathrm{s}$ \\
& & & Total & $1.30 \times 10^{-7} \mathrm{~m}^{3} / \mathrm{s}$ \\
\hline
\end{tabular}

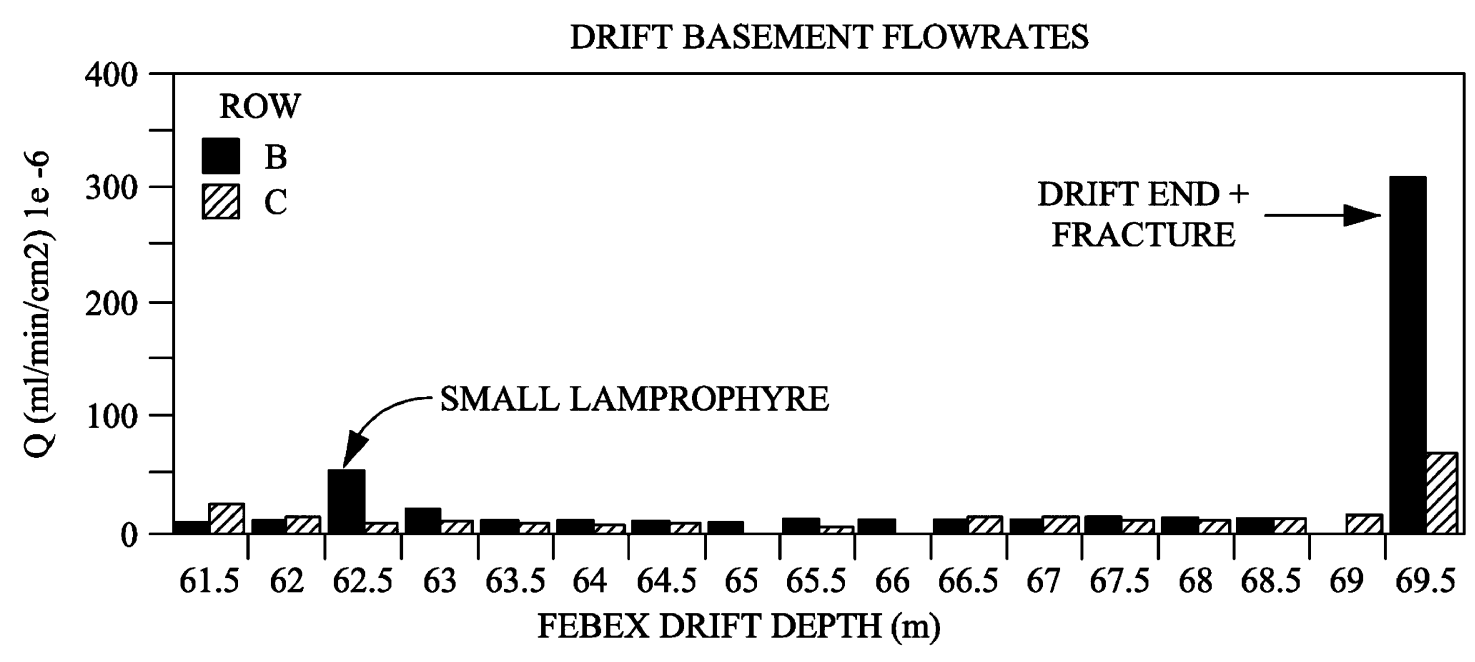

Fig. 14. Results of inflow measurements in part of FEBEX test area arranged in rows and their relationships to geological structures [2].

The total water inflow into the FEBEX tunnel was estimated to be $1.30 \times 10^{-7} \mathrm{~m}^{3} / \mathrm{s}$ (about $7.8 \mathrm{ml} / \mathrm{min}$ ). The total water inflow is made of the contributions coming from: (1) the matrix with an inflow of $3.51 \times 10^{-8} \mathrm{~m}^{3} / \mathrm{s}$, (2) the fractures with an inflow of $2.79 \times 10^{-8} \mathrm{~m}^{3} / \mathrm{s}$ and (3) the well-identified points with an inflow of $6.67 \times 10^{-8} \mathrm{~m}^{3} / \mathrm{s}$. From these results, it may be concluded that: (1) about the $27 \%$ of the water inflow is through the matrix (this flow, usually not considered, is important in this case) and (2) about the $51 \%$ of the water inflow is through well-identified points (conventional methods measure typically this flow).

The radial inflow into the tunnel was also estimated by means of the application of analytical expressions from well hydraulics, such as the Thiem formula:

$Q=\frac{2 \pi T \Delta h}{\ln (R / r)}$,

where $Q$ is the water inflow into a well interval, $T$ is the transmissivity of the considered well interval, $\Delta h$ is the head drop between a point located at a distance $R$ from the well center and a point located at a distance $r$ (on the well surface). This and similar formulae were employed with data obtained from the tests carried out in the instrumented intervals located on the FEBEX 95.001 and FEBEX 95.002 boreholes.

It is remarkable that the different measuring and estimation procedures mentioned produced similar inflow rates, in the range from 4.5 to $8.5 \mathrm{ml} / \mathrm{min}$. This is shown in Table 7, which provides the actual values for each of the different measuring procedures. Also included in the table are the predictions by the different Modelling Teams. Some of the predictions are quite accurate and a large proportion of the Modelling Teams find inflow rates in close proximity of the measured values.

In general, all Modelling Teams predicted values that were in the order of magnitude of the measured value of about $7.8 \mathrm{ml} / \mathrm{min}$. Moreover, most Modelling Teams (ANN, CNS, DOE, SKB and SKI) made good predictions. Largest deviations below or above measurements (ANG, IPS, JNC) are not specially serious in view of the high uncertainties commonly associated with "in situ" permeability properties and the overall complexity of the problem.

It should be noted that, out of the three Modelling Teams (ANN, IPS, SKB) that provided "blind" 
Table 7

Flow measurements and predictions by participants at day 100

\begin{tabular}{|c|c|c|c|}
\hline Measurements (Guimerà et al. [4]) & $\mathrm{Q}(\mathrm{ml} / \mathrm{min})$ & Team & $\mathrm{Q}(\mathrm{ml} / \mathrm{min})$ \\
\hline Estimation before tunnel excavation & \multirow[t]{2}{*}{8.0} & ANG & $0.13^{\mathrm{a}}$ \\
\hline (borehole hydro-geological tests + steady state radial flow formulae) & & ANN & 6.45 \\
\hline Discrete flow measurement during tunnel excavation & \multirow[t]{2}{*}{8.5} & CNS & 10.10 \\
\hline (absorbing pads on selected points of the tunnel wall) & & DOE & 10.10 \\
\hline Bulk flow measurement in January 1996 & \multirow[t]{2}{*}{4.5} & IPS & 34.53 \\
\hline (small gauge measuring the overall leaked water) & & $\mathrm{JNC}$ & 0.39 \\
\hline Discrete flow measurment in April 1996 & \multirow[t]{2}{*}{7.5} & SKB & 7.01 \\
\hline (absorbing pads on selected points of the tunnel wall) & & SKI & 6.94 \\
\hline Bulk flow measurement in May 1996 & \multirow{2}{*}{\multicolumn{3}{|c|}{6.7}} \\
\hline (small gauge measuring the overall leaked water) & & & \\
\hline
\end{tabular}

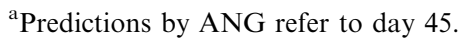

(without knowing the experimental value) predictions, one (SKB) gave a good value. After the experimental value was disclosed, one of these three Modelling Teams (ANN) found a calibration mistake that, when fixed, yielded a good prediction.

The comparison between measured and predicted pore water pressure records for the measuring interval P4, are presented in Fig. 15a and b. Pressure and tunnel drilling advance are plotted as a function of time. The position of the measuring interval (P4) along borehole FEBEX 95.002 is indicated by a vertical segment, which spans the appropriate tunnel metering. Predictions of modelling teams are indicated with the corresponding acronyms and selected format.

In order to fully appreciate the reasons for the performance of a given model, their features should be considered in detail. Four key factors are identified, namely: (1) initial stress, (2) full hydro-mechanical coupling, (3) permeability, and (4) realistic excavation process. Since permeability was calibrated during the prediction of the total water inflow to the test tunnel (particularly after the measured values were disclosed), attention is now directed to the other three factors. As shown in Table 8, each Modelling Team considered these factors in different ways, a fact that may explain the performance of the various predictions.

The early time water pressure measurements at $\mathrm{P} 4$, when tunnel drilling operations were not directly affecting the measuring intervals (from the 25th of September to the 20th of October, 1995), showed a steady but slow decrease in pressure, especially in later times (5th of October to 20th of October). Pressure was fairly stabilized at $0.66 \mathrm{MPa}$, Fig. 15 . Subsequent readings at $\mathrm{P} 4$ showed a fast increase in pore water pressure directly connected with the periods of tunnel drilling. The periods of drilling inactivity (night shifts, weekends and an approximate period of $14 \mathrm{~h}$, the 25 th of October 1995, can be identified in Fig. 15) were immediately reflected in a transient decay in pore water pressure. Once the tunnel face had gone beyond the P4 interval, a progressive decay of pore water pressure was monitored.

In general, the Modelling Teams had difficulties in modelling this part of the benchmark. The Modelling Teams that provided "blind" predictions (IPS and SKB) were unable to reproduce the peaks at interval P4. The predictions made by the Modelling Teams after the experimental curves were disclosed were generally poor, with the exception of two good predictions (CNS and SKI) and a fair prediction (ANG). The patterns of prediction are now very different from team to team. These differences are explained by the nature of the models being used and by the orientation and intensities of assumed initial stress.

Predictions without a full hydro-mechanical coupling (ANN, DOE and IPS) are characterised by a monotonous decrease in pore water pressures between the corresponding initial and final steady states. Since the full hydro-mechanical coupling is lacking, compressions (extensions) in the rock mass due to the excavation of the tunnel do not generate increases (decreases) of pore water pressure.

Predictions with full hydro-mechanical coupling (ANG, CNS, JNC, SKB and SKI) were able to predict non-monotonous pore water pressure evolutions. However, several distinctive features among these predictions could be noticed. Some predictions (ANG and a preliminary prediction by SKI) behave in a way opposite to observations: predicted pressure decreases during excavation times and increases during periods of inactivity. Some predictions (CNS and SKB) had both pressure increases and decreases during tunnel excavation periods. The model predicts rapid pressure dissipation and negative values once the tunnel goes beyond section P4. SKI presents more accurate predictions, although the selected "in situ" stress field does not correspond with available information.

The long-term reaction of the pressure measured in the borehole section $\mathrm{P} 4$ shows a steady decrease since the excavation of the tunnel implies a neighbouring 

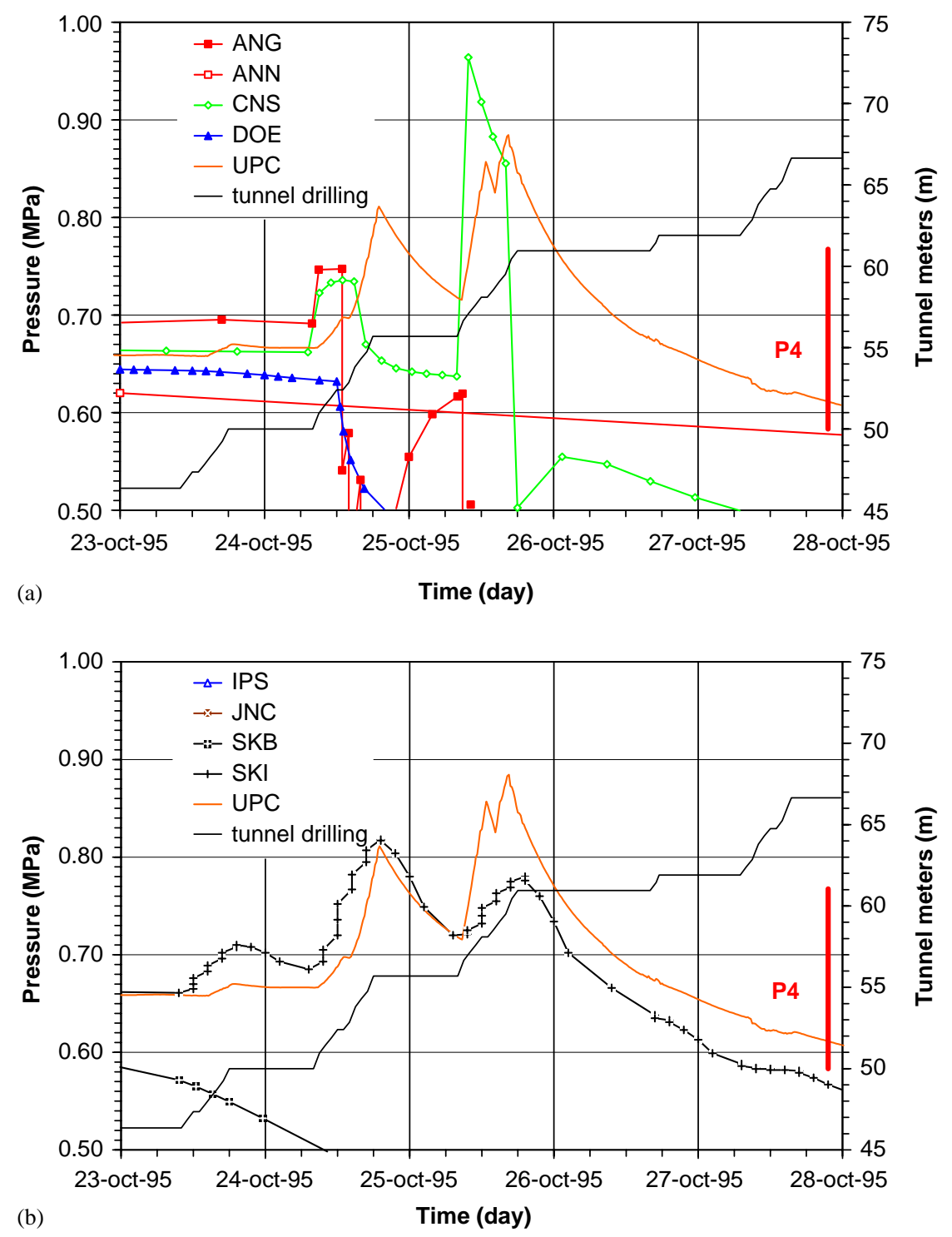

Fig. 15. (a, b) Water Pressure Evolution (borehole FEBEX 95.002, interval P4).

Table 8

Consideration of couplings and some key factors by the Modelling Teams

\begin{tabular}{|c|c|c|c|c|c|}
\hline \multirow[t]{2}{*}{ Team } & \multirow[t]{2}{*}{ Couplings } & \multirow[t]{2}{*}{ Dimens $^{\mathrm{a}}$} & \multicolumn{2}{|c|}{ "In situ" stress } & \multirow{2}{*}{$\frac{\text { Excavation }}{\text { (phases) }}$} \\
\hline & & & Magn. & Orient. & \\
\hline $\mathrm{ANG}$ & $\mathrm{M} \leftrightarrow \mathrm{H}$ & 3 & YES & YES & 27 \\
\hline ANN & $\mathrm{M} \rightarrow \mathrm{H}$ & 3 & YES & YES & 4 \\
\hline CNS & $\mathrm{M} \leftrightarrow \mathrm{H}$ & 3 & YES & NO & 5 \\
\hline DOE & $\mathrm{M} \rightarrow \mathrm{H}$ & 3 & YES & NO & 4 \\
\hline IPS & $\mathrm{M} \leftrightarrow \mathrm{H}$ & 2 & YES & - & - \\
\hline $\mathrm{JNC}$ & $\mathrm{M} \leftrightarrow \mathrm{H}$ & 3 & $?$ & $?$ & 7 \\
\hline SKB & $\mathrm{M} \leftrightarrow \mathrm{H}$ & 3 & YES & YES & 8 \\
\hline SKI & $\mathrm{M} \leftrightarrow \mathrm{H}$ & 3 & NO & NO & 12 \\
\hline
\end{tabular}

The abbreviation "magn." (respectively, “orient.") refers to the consideration of an initial stress field $\sigma_{0}$ whose principal stresses have magnitudes (respectively, orientations) in the range given in the case definition.

${ }^{\mathrm{a}}$ Dimensions of the model; 3: three dimensional model. boundary at a given relative humidity (the RH prevailing in the FEBEX tunnel prior to the buffer and heater installation). Most of the models show this trend although the rates of water pressure decay may change.

The initial state of rock stress was identified as a key factor in explaining the observed behaviour. Although the initial stress field leading to acceptable reproduction of the water pressure response was quite different from the initial stresses that could be expected according to the information available, it is recognized that the presence of shear zones and lamprophyre inclusions in the zone surrounding the test area could lead to widely inhomogeneous stress distributions.

Finally, it is expected that the accuracy of modelling the tunnel excavation should have a significant influence on the quality of the corresponding predictions. A key aspect is here the number of excavation phases. A small number (4-6) of excavation phases, used by some of the 
teams (Table 8 ) is probably not a sufficiently accurate representation of the evolving geometry. The maximum number of excavation phases (27) was selected by ANG.

\section{Discussion-Part A}

Widely different models for water inflow were used. Some teams (ANN, CNS, and SKB) used uncoupled hydraulic transient models to solve the first part of the exercise, whereas others (ANG, DOE, SKI) used a coupled HM modelling. It does not seem that the mechanical coupling introduces any advantage in this case. In fact, the reason for some of the better predictions (such as SKB calculation) may be associated with previous calibration of the model using other hydraulic data in the same area. Some models describe water circulation in the rock by means of discrete features (tubes and channels such as $\mathrm{ANN}$ ), equivalent porous medium for different zones (such as DOE, SKI) and others combine porous medium and discrete fractures (ANG, CNS, SKB). Again the overall results do not show a particular advantage of a given conceptualisation. Some of the calculations (such as SKI) provide the proportion of flow rates attributed to different origins (matrix, fracture zones).

Pore water pressure changes in the vicinity of the tunnel excavation are a direct consequence of changes in the volumetric strain of the rock. The pattern of pore water pressure dissipation is a consequence of the transition flow towards a new equilibrium, which now has a modified boundary condition (the tunnel surface) in the vicinity. Therefore, fully coupled hydro-mechanical analyses are required to try to capture actual measurements. One-way coupling (hydraulic parameters updated as the rock mass deforms) is not capable of reproducing the observed behaviour.

However, the case has demonstrated that even if a fully $\mathrm{HM}$ coupled model is used, the difficulties to simulate the actual pore pressure of the granitic mass are very high. It was well established that the volumetric behaviour of the rock in the vicinity of the tunnel depends critically on two aspects: the orientation and the intensity of the initial stress field. "In situ" stresses show often a large variability. Field determinations at Grimsel suggest that the major principal stress at the location of the FEBEX tunnel is horizontal (around $30 \mathrm{MPa}$ ), whereas the minor principal stress may be considered vertical and defined by geostatic conditions (around $10 \mathrm{MPa}$ ). The intermediate principal stress, also horizontal, may reach intermediate (around $15 \mathrm{MPa}$ ) values, but remains substantially higher than the vertical stress. It was shown that this particular distribution of initial stress leads to results which are opposite in trend to the actual measurements (dilation of the rock, instead of compression is computed at the P4 locations). In order to match the actual measurements, changes in the intensity of the vertical stress and on the direction of principal horizontal stresses had to be introduced. For example, SKI decided to choose an initial "in situ" stress field that agreed neither in magnitude nor in orientation with the corresponding information provided in the case definition: $\sigma_{\mathrm{v}}=22.5 \mathrm{MPa}, \sigma_{\mathrm{H}}=$ $30 \mathrm{MPa}$ and $\sigma_{\mathrm{h}}=15 \mathrm{MPa}$, with an orientation of the horizontal minimum stress $\sigma_{\mathrm{h}}$ parallel to the tunnel axis. Moreover, the same initial stress field does not seem to be valid to reproduce results at P3 and P4. The finite length of the measuring intervals allows also an easy connectivity between pervious and impervious zones.

Part B: Thermo-hydro-mechanical analysis of the buffer behaviour

\section{Overview of physical processes in the bentonite barrier}

Fig. 16 shows a general scheme of the main hydrothermal processes taking place in the buffer. The figure shows a cross-section of the buffer and the near field. A heat flow is introduced at the canister-bentonite interface and it is conducted away through the buffer and the rock towards the outer boundary. The saturated granite provides the water to progressively saturate the bentonite, initially unsaturated. A net inflow of liquid water is sketched flowing in opposite direction to the heat flow. Conductive and advective fluxes of heat take place in the granite. Within the unsaturated bentonite, water exists in two phases (liquid and vapour) and this leads to evaporation and condensation phenomena in hot and cool zones of the buffer as indicated in the figure. Heat now flows through conductive and advective mechanisms in the three phases considered (solid, liquid and gas). A diffusive vapour flow adds to the advective liquid term to define the total flow of water within the barrier. Finally, as a result of changes in water content (alternatively measured in terms of relative humidity or suction), the bentonite shrinks or swells and develops, when wetted, significant swelling stresses which modify the stress state of buffer and surrounding rock.

Measured data display some characteristic trends which are a result of the outlined physical processes. A few variables have been selected to show the buffer behaviour. Field measurements have been represented in a number of plots (Figs. 17-22) with the acronym "UPC". Also indicated in the plots are model predictions, which will be discussed later in some detail. The comments below refer only to the following measured data:

Heating power (Fig. 17): After switching to automatic control (aiming at keeping the maximum temperature in the heaters at $100^{\circ} \mathrm{C}$ ), the heating power initially decreases and after about 1 year of operation, it 


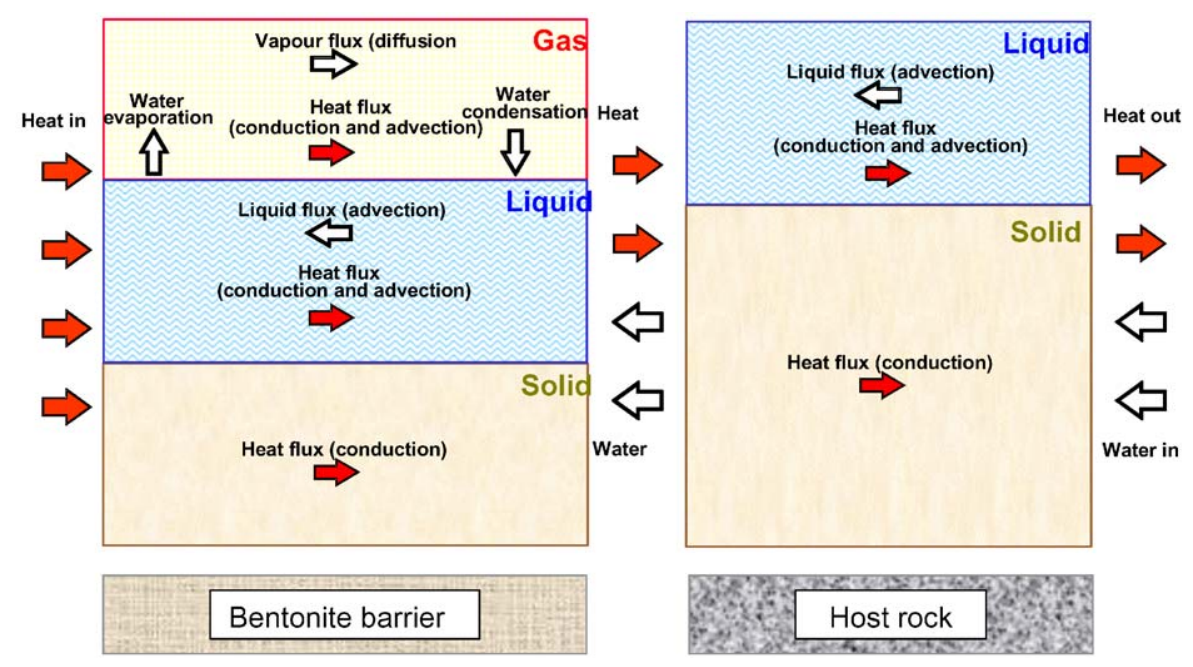

Fig. 16. Scheme of thermo-hydraulic processes in the near field [18].

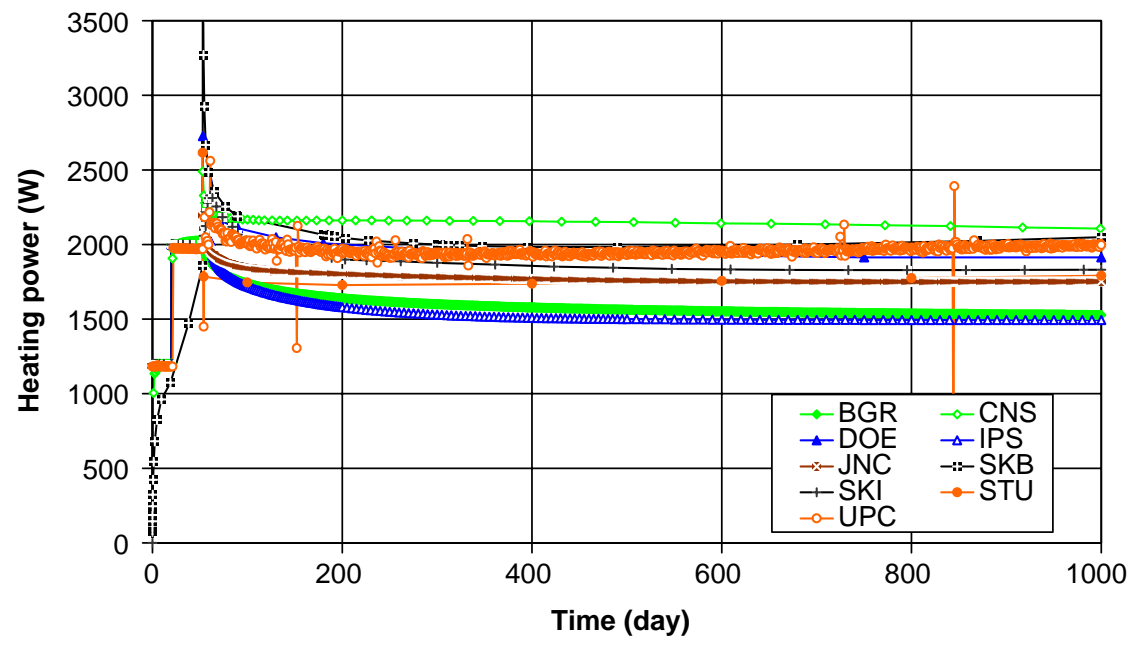

Fig. 17. Measured and predicted evolution of heating power. Heater 1.

increases slightly without reaching a steady value during the first 1000 days of operation.

Relative humidity (Figs. 18-20): Points in the buffer located near the granite become rapidly saturated, points near the heater experience an intense desiccation and points near the centre of the bentonite buffer exhibit a more complex behaviour, whereby they initially become wetter reaching a maximum at about the 80 days of operation. Later they rapidly dry and finally they progressively become hydrated.

Temperature (Fig. 21): Experimental measurements of temperature along the various radial directions are similar and steady state distributions are approached rather quickly.

Total stress (Fig. 22): Rather complex total stress evolutions have been recorded, with different patterns even at points located at the same radial distance. A progressive development of stresses is recorded in the section shown in Fig. 22. It should be born in mind that stress measurements are subjected to difficulties due in part to the blocky nature of the bentonite buffer.

\section{Modelling approaches for Part B}

Each Modelling Team used a particular model whose parameters were determined on the basis of the information provided with the case definition, references found in the literature and its own modelling experience. Main features of different models are given in Table 9. A few relevant physical phenomena have been isolated to prepare this table. The first column describes the main couplings considered. A fully coupled thermo-hydromechanical approach built in the calculation procedure 

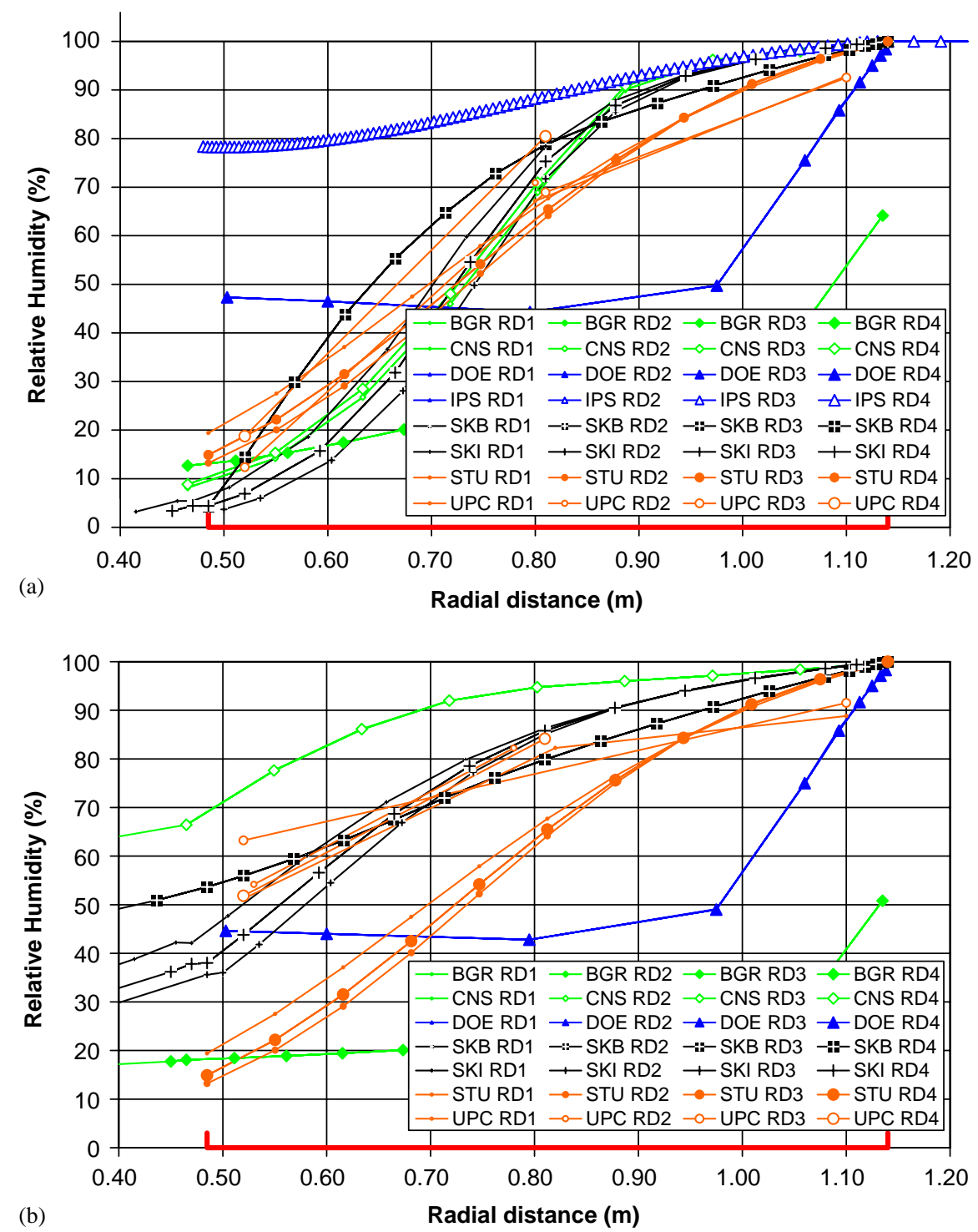

Fig. 18. (a) Variation of relative humidity with radial distance in Section E1 for $t=1000$ days; (b) Variation of relative humidity with radial distance in Section $\mathrm{H}$ for $t=1000$ days.

is indicated as "THM". Two of the Modelling Teams did not introduce mechanical effects (TH). Finally, two teams used two separate programs (thermo-hydraulic and hydro-mechanic, respectively), which were linked in the sense indicated: mechanical effects were derived as a result of thermal and hydraulic changes. The reverse effect was not introduced in those cases.

Gas flow was considered by one team. All of them modelled liquid flow and permeability was made saturation dependent. Vapour flow and phase change (liq $\leftrightarrow$ gas) was considered by a subset of teams. Heat conduction was also a common feature of all models and the thermal conductivity in the buffer was in some cases made dependent on the bentonite degree of saturation.

Model calibrations varied very significantly among participating teams. The best approaches involved the backanalysis of some of the suction controlled tests made on bentonite behaviour.

\section{Comparison of field data with model calculations for Part B}

Fig. 17 shows the evolution of measured input electrical power on heater 1 and the set of predictions. Most of calculations reproduce the progressive decrease of required power but only in one case (SKB) the reverse trend experienced after some time is well reproduced.

The variation of relative humidity with radial distance in Section E1 is shown, in Fig. 18a, for $t=1000$ days. Measured data of four radial directions (two vertical, two horizontal) are lumped together in the figure. The 

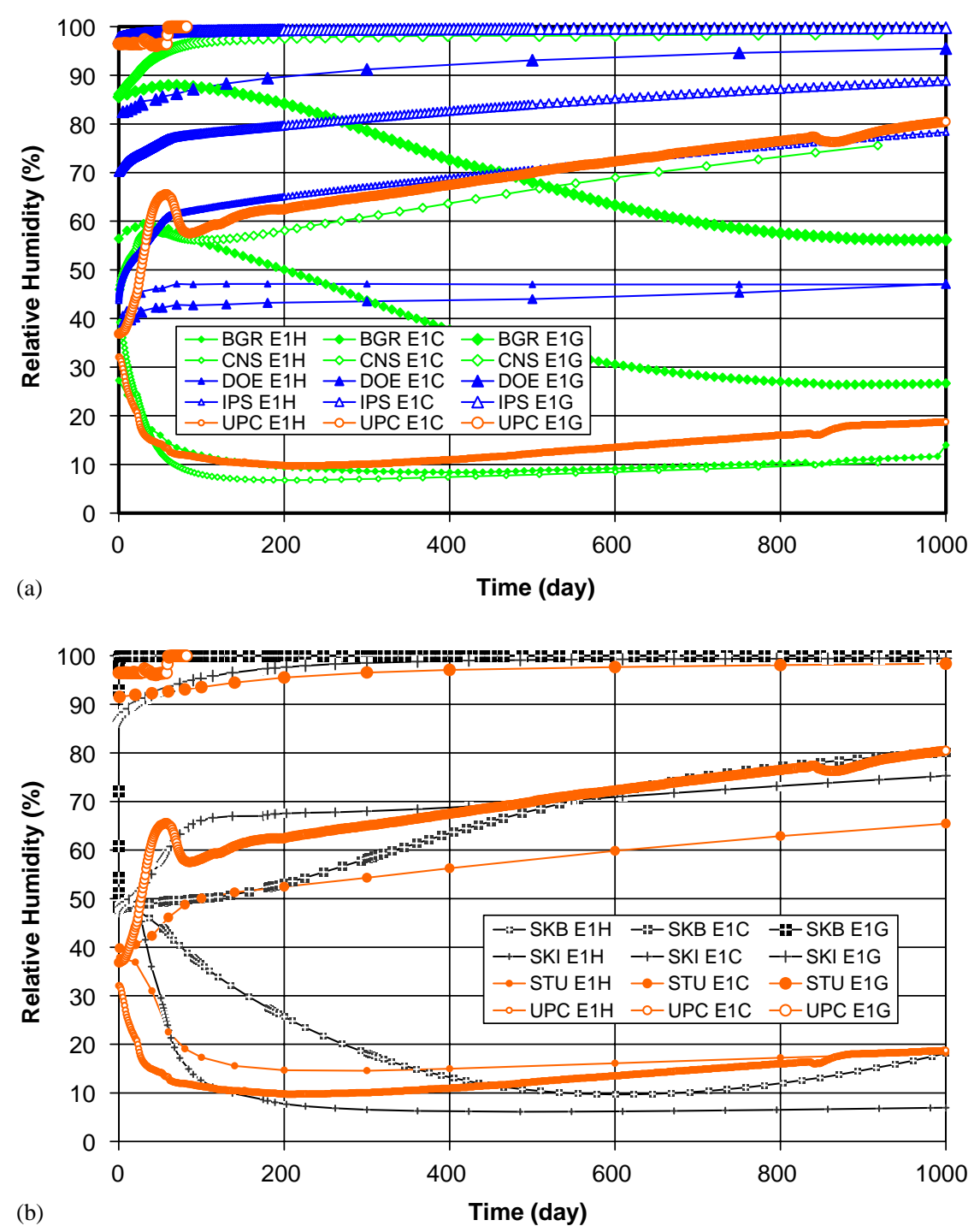

Fig. 19. Measured and predicted variation of RH at three radial points in Section E1 (H: heater; C: center; G: granite).

measured data does not show a clear preferential direction of hydration. The test response seems to have a cylindrical symmetry. This is an interesting observation since a lamprophyre dyke, which provided a nonuniform inflow of water into the tunnel, crossed Section E1. Some of the predictions capture well the distribution of Relative Humidity. Others have difficulties to handle the change of phase of water at the hot areas and predictions are far from reality. In one case (SKI) the 3D analysis performed leads to small variations of relative humidity with the different radial orientations, a result that is partially supported by the experimental evidence.

A similar plot is given in Fig. $18 \mathrm{~b}$ for Section $\mathrm{H}$, centered between the two heaters and, therefore, not directly affected by the heat released by them. This section is obviously wetter. Predictions require now a 2D axisymmetric (or 3D) geometry. Two of the models predict quite accurately the experimental data.

Evolution plots of relative humidity at some selected points $(\mathrm{H}, \mathrm{C}$ and $\mathrm{G})$ are given in Figs. 19 (Section E1) and 20 (Section $\mathrm{H}$ ). Measurements exhibit a very distinctive pattern. The point close to the granite $(\mathrm{G})$ becomes rapidly saturated. The point in the bentonite close to the heater $(\mathrm{H})$ experiences an intense desiccation. The initial RH decreases to values as low as $10 \%$ (this is equivalent to a very high suction: more than $300 \mathrm{MPa}$ ) 200-300days after the beginning of heating. Later, the humidity increases at a slow, progressive rate. The point in the center (C) displays a more complex behavior: it becomes initially wetter, reaches a peak value of RH, but partially dries immediately afterwards. These transient phenomena take place during the first 80 

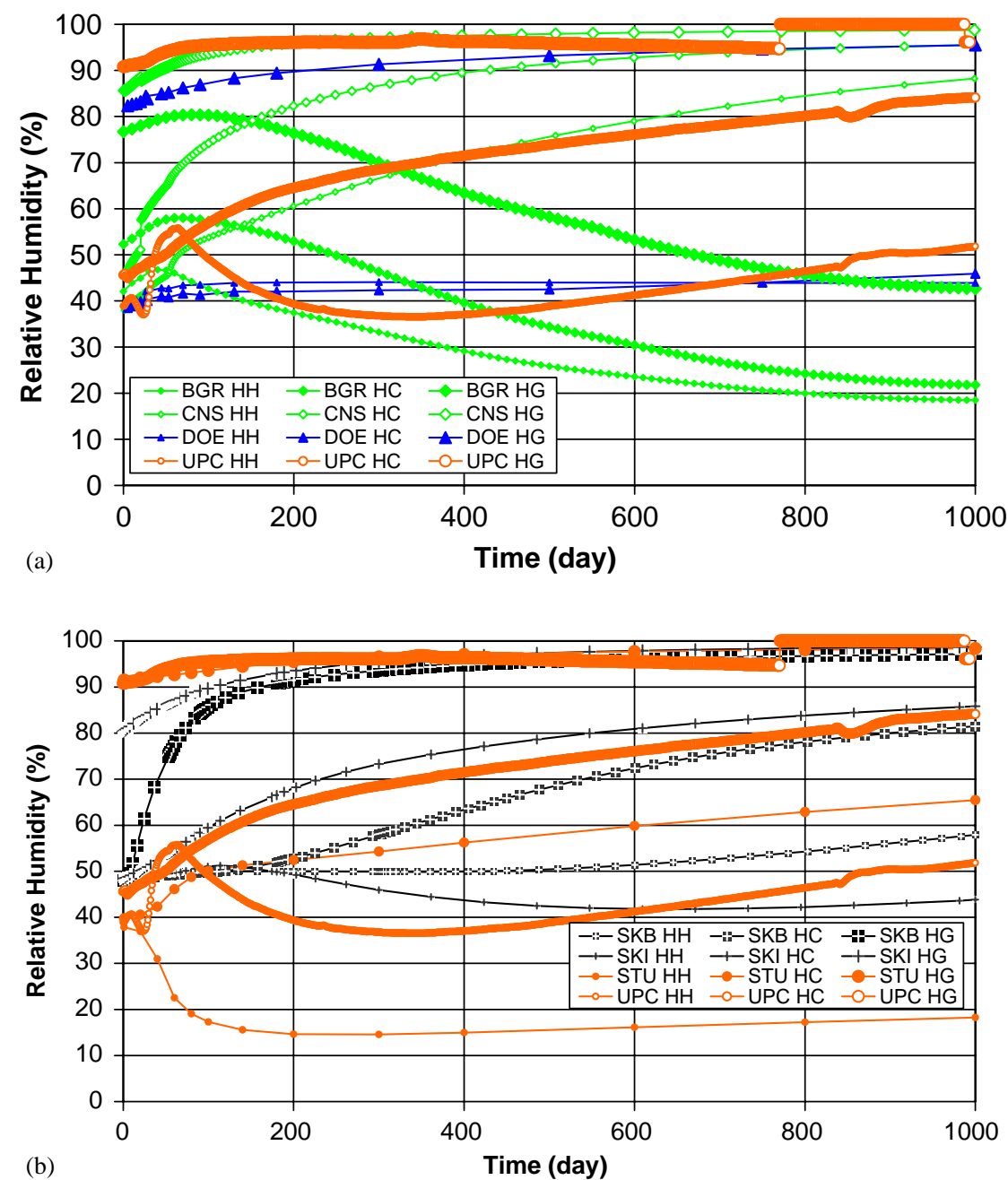

Fig. 20. Measured and predicted variation of RH at three radial points in Section H (H: heater; C: center; G: granite).

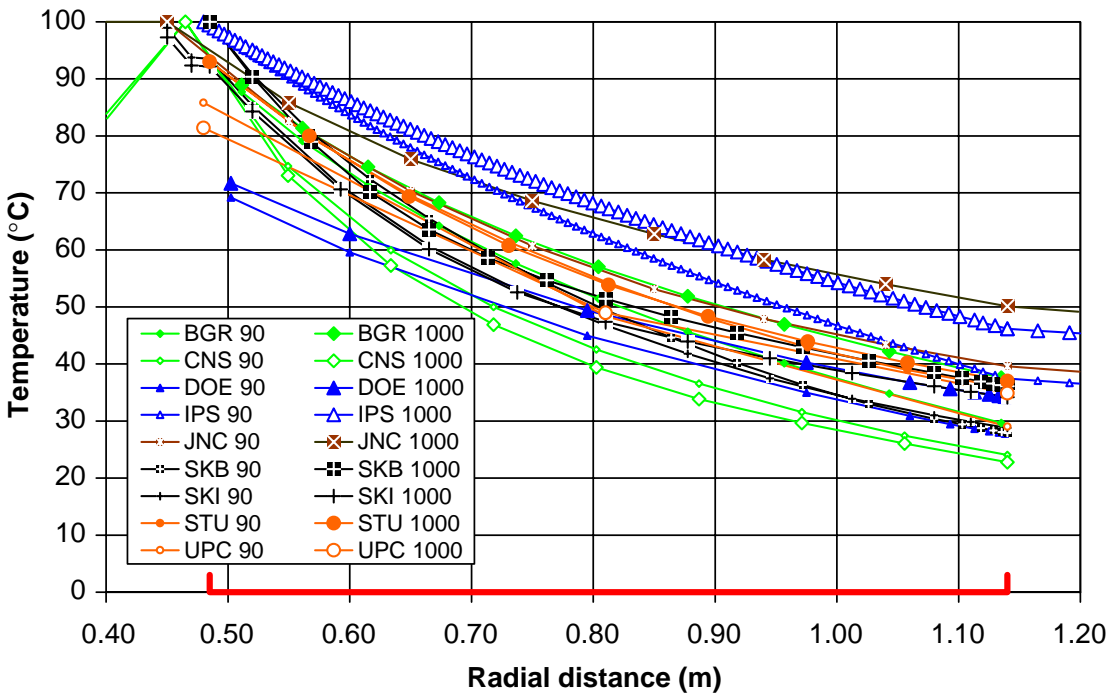

Fig. 21. Measured and calculated temperature variation across the barrier, at Section D1, for two times: 90 and 1000 days. 

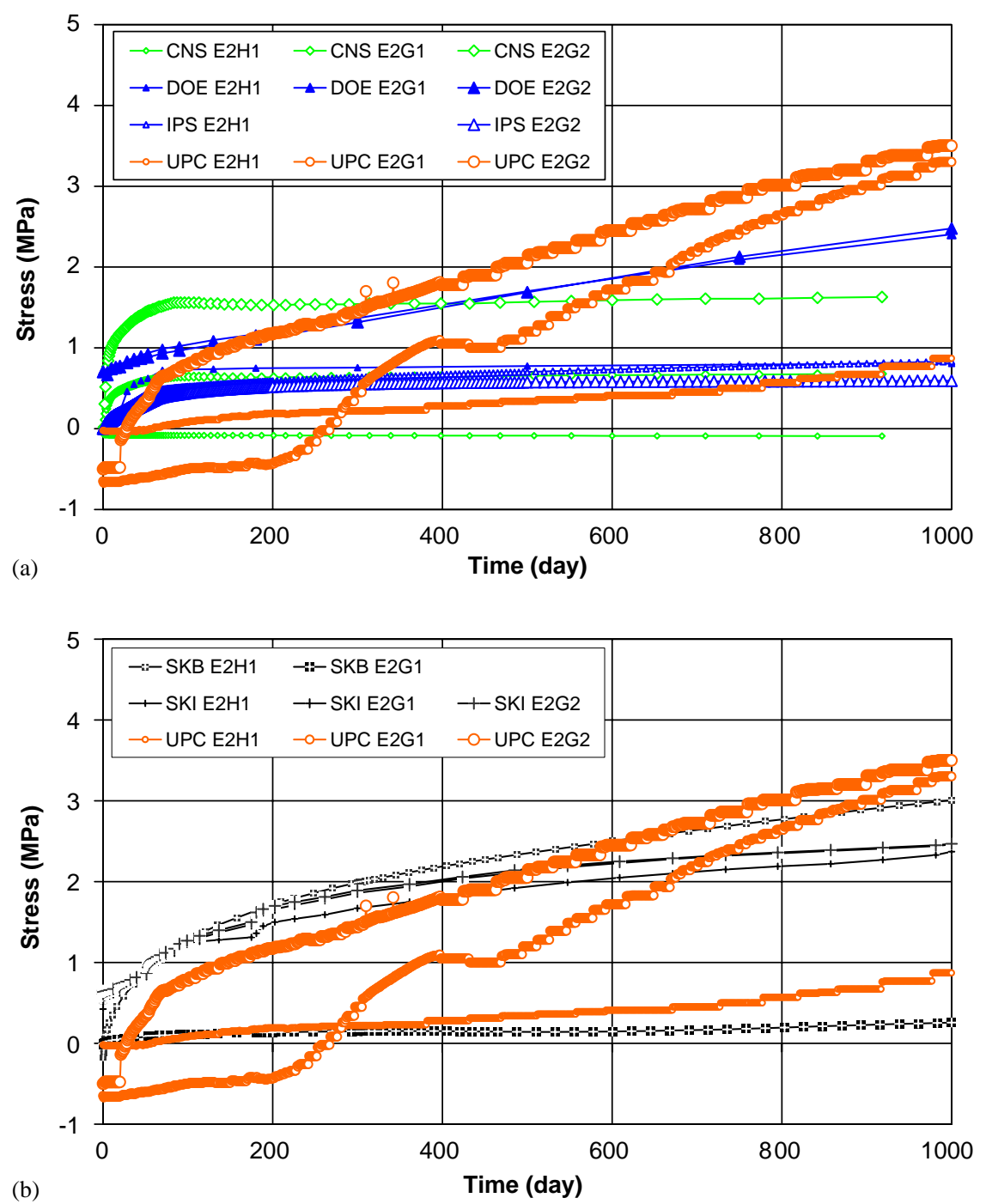

Fig. 22. Measured and predicted variation of RH at three points in Section E2 (H: heater; C: center; G1 and G2: granite).

Table 9

Main features of the models used for Part B

\begin{tabular}{lllllll}
\hline Team & Couplings & Deform. & Wat. flow & Vap. flow & Liq $\leftrightarrow$ gas & Gas flow \\
\hline ANG & - & - & - & - & - & - \\
BGR & TH $\rightarrow$ HM* & & $\bullet$ & $\bullet$ & $\bullet$ & $\bullet$ \\
CNS & THM & $\bullet$ & $\bullet$ & $\bullet$ & $\bullet$ \\
DOE & TH $\rightarrow$ TM & $\bullet$ & $\bullet$ & $\bullet$ & $\bullet$ \\
IPS & THM & $\bullet$ & $\bullet$ & $\bullet$ & $\bullet$ \\
JNC & TH & THM & $\bullet$ & $\bullet$ & $\bullet$ & $\bullet$ \\
SKI & THM & $\bullet$ & $\bullet$ & $\bullet$ & $\bullet$ \\
STU & TH & & $\bullet$ & $\bullet$ & $\bullet$ \\
\hline
\end{tabular}

In the BGR model, $\mathrm{M}^{*}$ indicates that the mechanical part reduces to consider a dependency on the swelling pressure.

days of heating. Later, a progressive hydration is recorded. Some of the model results reproduced in Fig. 19 capture correctly this phenomenon. The difficulties found by others are associated with incom- plete formulations of the phase change of water and the transportation of water vapour. One thousand days after the beginning of heating the barrier is still far from saturation. 
A more complex initial transient is measured at the inner point in Section H (Fig. 20). The central and outer points exhibit a progressive hydration from the early stages. One of the model predictions in Fig. 20 (SKI) is remarkably accurate.

Only one figure regarding temperature distribution across the barrier is included here (Fig. 21). At the particular location shown (Section D1 at the edge of Heater 1), temperature decreases from a value above $80^{\circ} \mathrm{C}$ at the heater to $30-35^{\circ} \mathrm{C}$ at the granite contact. The lower value $\left(30^{\circ} \mathrm{C}\right)$ corresponds to 90 days of heating and the upper one $\left(35^{\circ} \mathrm{C}\right)$ to 1000 days of heating. All the predictions follow the measured decay with reasonable accuracy. However, when comparing extreme predictions for a common time (1000 days) a maximum difference of $27^{\circ} \mathrm{C}$ is found.

Measured radial stresses are given in Fig. 22a, b. Two of the selected measurement cells (G1 and G2) are at the contact between the bentonite blocks and the granite wall. The third one (H1) is closer to the heater. The outer cells develop consistently stronger radial stresses than the inner one during the considered time span. Stress build-up is faster in one of the $G$ cells but the recorded radial stress in both cells is similar and close to $3.5 \mathrm{MPa}$ at the end of the measuring period. The inner cell, however, shows a slower and steady development of the confining stress. The recorded value at the end of the period has not reached $1 \mathrm{MPa}$. It is clear that the buffer is still far from reaching the full swelling potential of the bentonite (about $6 \mathrm{MPa}$ ). One of the modelers (SKB in Fig. 22b) made a very good prediction although the predicted rate of increase of stress at the end of the period is slower than the actual value. Some models (IPS, DOE, SKI) predict a similar stress development in the inner and outer positions considered. Most of them underpredict, to a different degree, the actual measurements, especially at later times.

\section{Discussion-Part B}

The heating power is a global variable of the barrier performance dominated by the heat conductivity of buffer and rock. The initial strong drying of the inner part of the bentonite leads to a reduction of the heat conduction coefficient and, therefore, a reduction in power is required to maintain a constant temperature at the heater-buffer contact. As the buffer becomes progressively saturated in the mid and long term, the average heat conductivity of the bentonite increases and the required heating power should increase. Models which do not include a dependence of $\lambda_{\mathrm{T}}$ on $S_{r}$ cannot reproduce this effect. Surprisingly, only one of the predictions (SKB) matched correctly the actual behaviour.
The distribution and evolution of relative humidity offers a very good image of relevant thermal and hydraulic phenomena taking place in the barrier. Early stages of heating are dominated by phase changes in the inner part of the buffer. Evaporation close to the heater and condensation of the outwardly migrating vapour flow explain the observed changes in relative humidity. Models which do not include vapour generation and flow (BGR, IPS, JNC) cannot reproduce the measurements.

One of the relevant features of the measurements is the transient drying-wetting-drying and final wetting of points located in the inner rings of the buffer. This behavior is explained by the role of water vapour and phase changes in water transfer inside the barrier. Water evaporates in areas of the bentonite close to the heater. Hot vapour at high concentration migrates outward and becomes eventually cooler thus leading to condensation. This explains the peak observed in RH. This is an expanding process. As the temperature increases inside the barrier, this phenomenon moves in a radial direction and the inner points of the barrier become drier again. At higher times the water inflow (in liquid phase) from the outer zones eventually dominates the barrier hydration. Models that include a correct TH coupling, as outlined above, are capable of reproducing the observed behaviour. This is specially the case for some predictions affecting cross-section through the center of heaters. The recorded behaviour of some points in the central section is more complex and it was not reproduced accurately by any model. Preferential vapour flow paths along open joints, which may have played a role in this case, were not considered in any of the models used.

Relative humidity changes are weakly related to stress changes, provided the changes in void ratio (or joint openings among bentonite blocks) are not significant. It is expected that the joints in the inner part of the buffer remain open during the simulation period considered in the analysis. Joints of the outer buffer will certainly close and this change may affect, to a certain extent, the convective flow of water. However, in global terms, the porosity of the buffer remains constant due to the rigid confinement offered by the rigid granite. Therefore, changes in intrinsic permeability coefficients, induced by stress variations, are expected to be low. Accordingly, the correct prediction of relative humidity changes does not require a mechanical coupling. This is the case of STU which is able to reproduce in a satisfactory manner relative humidity changes in the buffer.

Another issue refers to the dimensionality of the problem. One-dimensional coupled modelling (IPS) is capable of making good predictions in cross-sections centered in the heaters. Axial symmetry is a good simplification in this case. Obviously, the central section 
of the test requires $2 \mathrm{D}$ or $3 \mathrm{D}$ analysis. The effect of discrete conducting features of the rock (shear zones, lamprophyre-granite contacts) on buffer hydration was, according to measurements of $\mathrm{RH}$ distributions along different axis of a given cross-section, of minor relevance. It is concluded that the low permeability of the saturated bentonite, $\left(1 \times 10^{-21} \mathrm{~m}^{2}\right)$ compared with the granite matrix permeability $\left(5 \times 10^{-19} \mathrm{~m}^{2}\right)$, leads to a fairly homogeneous hydration of the barrier. In other words, bentonite permeability controls its own rate of hydration and the rock matrix is capable of providing all the required flow of water. One of the 3D analyses (SKI) included in a simplified manner the actual position of the conductive rock features. The results obtained indicated a minor effect of the concentrated water inflows. Therefore, 2D axisymmetric models provide good results in this case.

Temperature distributions and evolutions offer limited information to discriminate the physical phenomena taking place in the buffer. Somewhat unexpectedly, temperature predictions varied significantly among modelling teams. The actual recorded values tend to remain at the average of all calculations.

Stress predictions require fully coupled THM models. Recorded radial stresses display the development of the swelling potential of the bentonite as it becomes wetter. However, the inner zones experience a strong drying which induces the shrinkage of blocks and favours the concentration of stresses at some contacts. Radial stresses recorded in the outer part of the buffer have shown a continuous increase during the observation period and their value is in excess of $3 \mathrm{MPa}$ at the end of the first 1000 days of testing. However, the cell located in the inner part of the buffer remained essentially unloaded during the same period. Some models reproduce this trend (SKB, CNS, DOE) whereas others (SKI, IPS) predict a rather homogeneous development of stresses within the buffer.

In general, models indicate a faster initial stress increase than the actually recorded evolutions, probably due to joint closure. At later dates, however, measured stresses maintain a constant rate of increase, unlike most models, which show a decreasing rate of increase. Model behaviour is a typical one for stress development associated with an underlying swelling mechanism induced by transient flow. The kinetics of swelling stress development in the bentonite is probably a more complex phenomenon.

Despite all the difficulties mentioned, some of the fully coupled 2D and 3D analyses, and notably those presented by SKI and SKB, have achieved a good overall representation of the buffer response against the combined action of internal heating and external wetting.
Part C: Thermo-hydro-mechanical analysis of the rock

\section{Features of the experimental data}

Several instruments were located, at increasing depth, in the 19 auxiliary boreholes, perforated in radial directions from the FEBEX tunnel (Fig. 1). An enlarged view of the borings is given in Fig. 23. The length of these radial boreholes does not exceed $15 \mathrm{~m}$. Typically, readings are available in three or four positions: close to the tunnel wall (say at 1-3 $\mathrm{m}$ distance from the origin of the boring, one or two intermediate distances and a distant position (13-14 $\mathrm{m}$ deep). The Cartesian coordinate system shown in Fig. 23 was used to orientate and locate the measuring devices.

Data is available on the following variables: temperature, water pressure in rock, water pressure in packers, stress state and radial displacements.

Water pressure was measured in some boring intervals (a few meters long) separated by packers. The rubber packers were also filled with water and their pressure was maintained and measured externally. Water pressure gauges are located in the measuring area of the FEBEX tunnel. They are connected with the measuring intervals by means of steel tubing.

Three normal components of stress are measured by means of total pressure cells. Four sets of 3 cells were prepared and grouted "in situ" in boreholes SG1 and SG2. Each cell had five sensors oriented in different directions and fixed on a common support $2 \mathrm{~m}$ long. Each one of the sensors was a circular steel flat cell. An interpretation of the five readings provides the normal stress components in three directions: radial (with respect to the tunnel axis) $\left(\sigma_{\mathrm{r}}\right)$, axial (along the direction of tunnel axis) $\left(\sigma_{x}\right)$ and circumferential $\left(\sigma_{\theta}\right)$. Once the sets were in position the borehole was filled with a

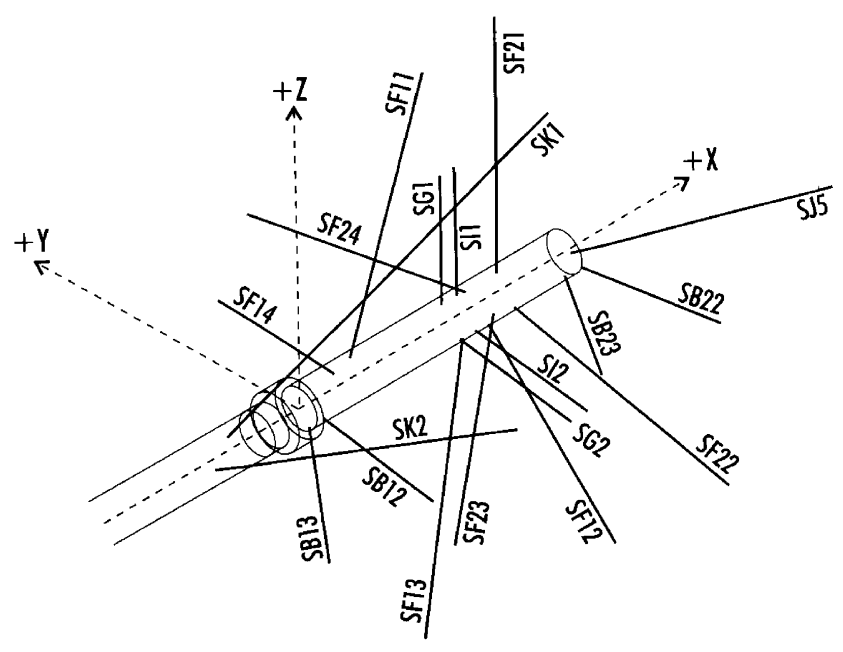

Fig. 23. Auxiliary instrumentation boreholes around FEBEX test section. 
slightly expansive mortar. Once the mortar was cured, cells were pressurized against the mass of surrounding mortar to guarantee a good initial contact. This procedure provides increments of stress over the stress state prevailing at the moment of cell installation. It will record therefore stress increments due to temperature effects, modification of pore water pressures and swelling of the bentonite.

Radial displacements were measured by means of borehole extensometers installed in borings SI1 and SI2. They were located close to the position of the stress cells. Each extensometer consists of graphite rods with independent anchoring points located at a depth of $1.0,3.0$ and $7.0 \mathrm{~m}$ into the borehole.

Plots showing the measured evolutions of temperature, pore water pressure, total stress and radial displacements are given in Figs. 24-28 ("UPC" acronym).

Temperature (Fig. 24) exhibits a monotonously increasing pattern. Temperature increases faster during the first two months after which they slowly approach asymptotic values.

Measured pore water pressures near the tunnel wall increase slowly in a monotonous way from a value close to $0.5 \mathrm{MPa}$ to a value around $0.7 \mathrm{MPa}$. No marked transients in pore water pressures were observed (Fig. 25). It is interesting at this point to observe the data of the packer pressures. The evolution of water pressure in the first packer located in borehole SF21 at a radial distance of $1.86 \mathrm{~m}$ is shown in Fig. 26. The initially recorded water pressure is related to the pressure applied to the packer to seal the borehole. Afterwards, the circuit is closed to maintain constant volume conditions. The substantial increase in pressure observed in Fig. 26 (maximum values close to $5 \mathrm{MPa}$ are recorded) is most probably due to the temperatureinduced dilation of the water inside the packer system.
Presumably, the deformation of the packer and measuring system and/or minor leaks led to a progressive decay afterwards. The relevant point is that this type of behaviour was not observed in the water pressure measuring intervals in direct connection with the granitic rock. Apparently, excess pore water pressures dissipate immediately after they are induced. In addition, recorded water pressures are average values over the measuring interval. This effect contributes also to reduce the excess pore water pressures. The different conditions of the packer system (a "high" porosity and a rigid confinement) explain the completely different behaviour recorded.

The evolutions of all the three measured total stress components (Fig. 27) are characterised by an initial fast increase until a peak is reached at about 100 days, followed by a slow and slight decrease and an even slower increase, without, however, approaching any asymptotic value during the period of 1000 days. Measured total stresses decrease significantly with the distance.

Measured maximum radial displacements were in the range of about 100 microns (Fig. 28). Their evolutions exhibit an initial fast increase followed by a very small subsequent increase. The magnitude of these displacements and their evolutions cast doubts on their accuracy.

\section{Comparison of field data with model calculations for Part C}

The model developed for Part B was used for Part C by most of Modelling Teams. A summary of the modelling approaches is given in Table 10. The inclusion of thermal dilation properties of rock and water is now necessary to tackle Part C. A full THM coupling is also needed to make meaningful predictions.

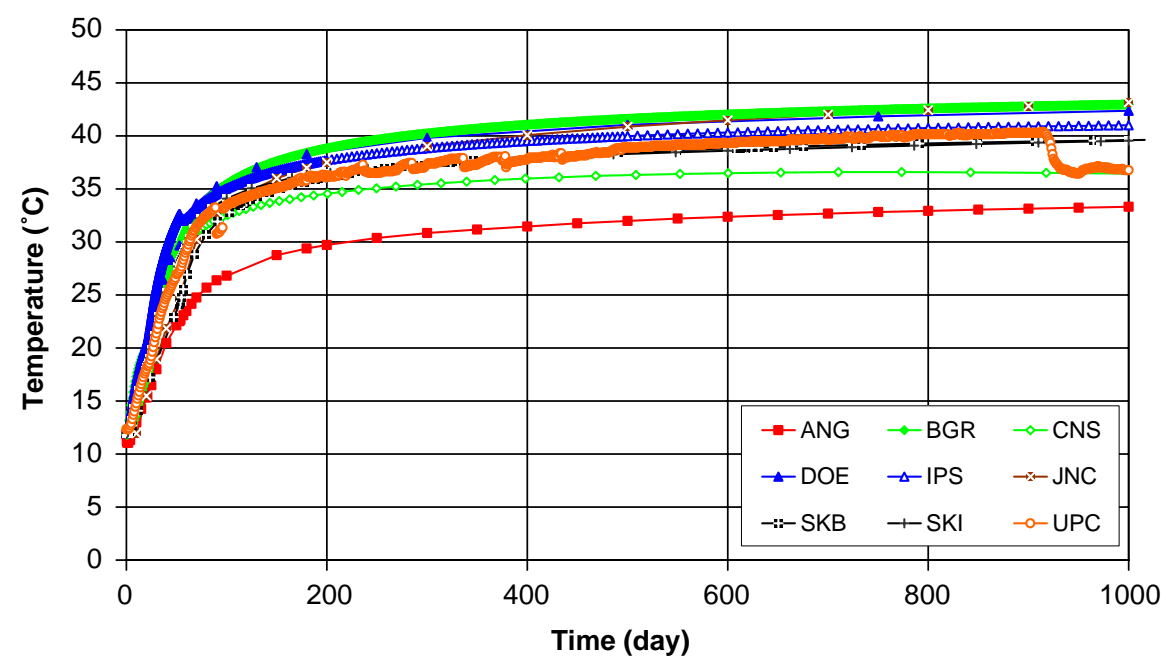

Fig. 24. Measured evolutions of pressures at borehole SF21. Water pressure at the packed off interval closest to the tunnel (centre at $r=3.03 \mathrm{~m})$ and inflation pressure of the packer closest to the tunnel (centre at $r=1.86 \mathrm{~m}$ ). 

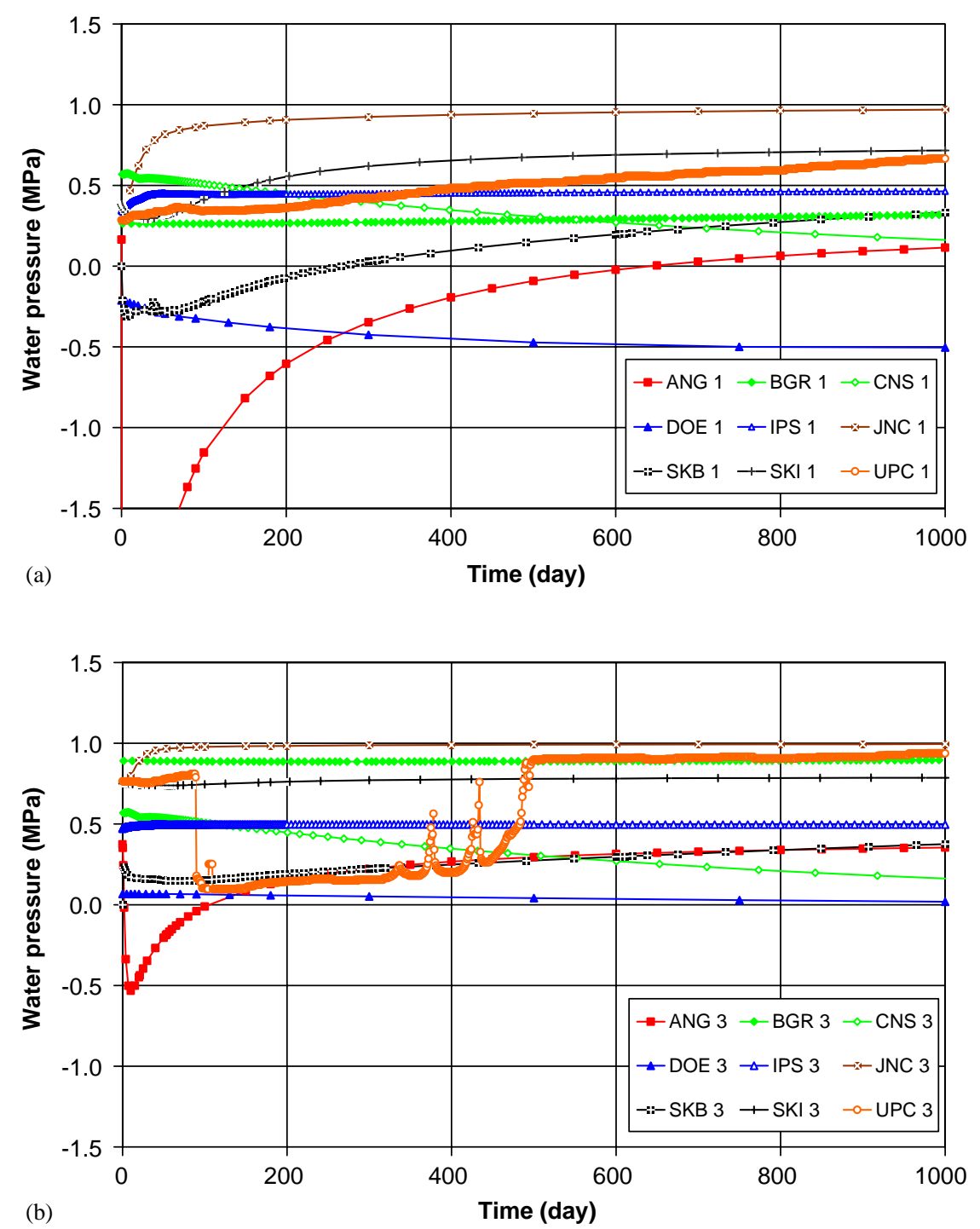

Fig. 25. Measured and predicted evolution of temperature in borehole SF 21 at a radial distance of $1.20 \mathrm{~m}$.

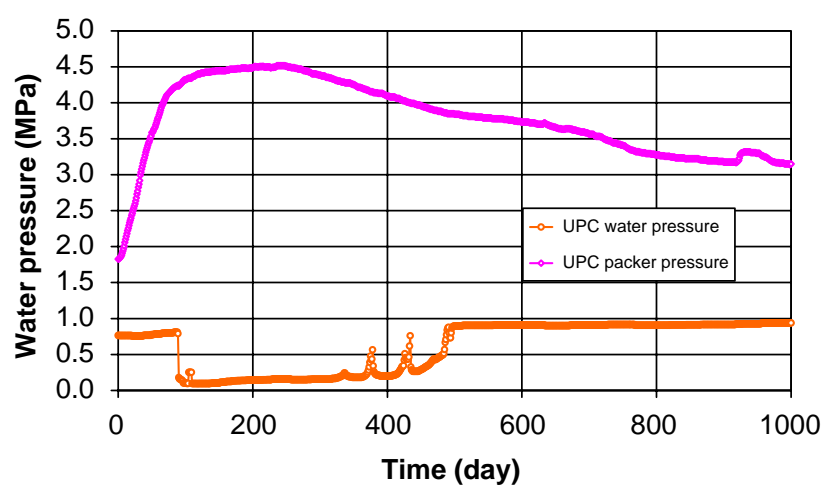

Fig. 26. Measured and predicted evolution of water pressures in borehole SF 21 at radial distances of 3.03 and $13.6 \mathrm{~m}$, respectively.

Measured and computed evolutions of temperature in Boring SF 21, at a radial distance of $1.20 \mathrm{~m}$ are shown in Fig. 24. Most predictions are quite accurate. Two of them, however, depart in a significant way. Prediction of temperature depends essentially on a correct estimation of thermal conduction coefficients and boundary conditions.

Water pressures are represented in Fig. 25a and b. Both figures show evolutions of water pressures recorded in Borehole SF 21 at radial distances of $3 \mathrm{~m}$ (Fig. 25a) and $13.6 \mathrm{~m}$ (Fig. 25b). These radial distances locate the centre point of the measuring intervals, which have lengths of 2.34 and $2.82 \mathrm{~m}$, respectively.

Some of the predictions made are very good and reproduce the absolute measured values and the increasing trend with time (IPS, DOE, and SKI). Measured water pressures are stable and close to $1 \mathrm{MPa}$ at the more distant point (Fig. 25b).

Recorded normal stresses in borehole SG2 $\left(\sigma_{x}, \sigma_{\theta}, \sigma_{\mathrm{r}}\right)$, are reproduced, together with predictions of several teams in Fig. 27a-c. Measuring cells were located at 

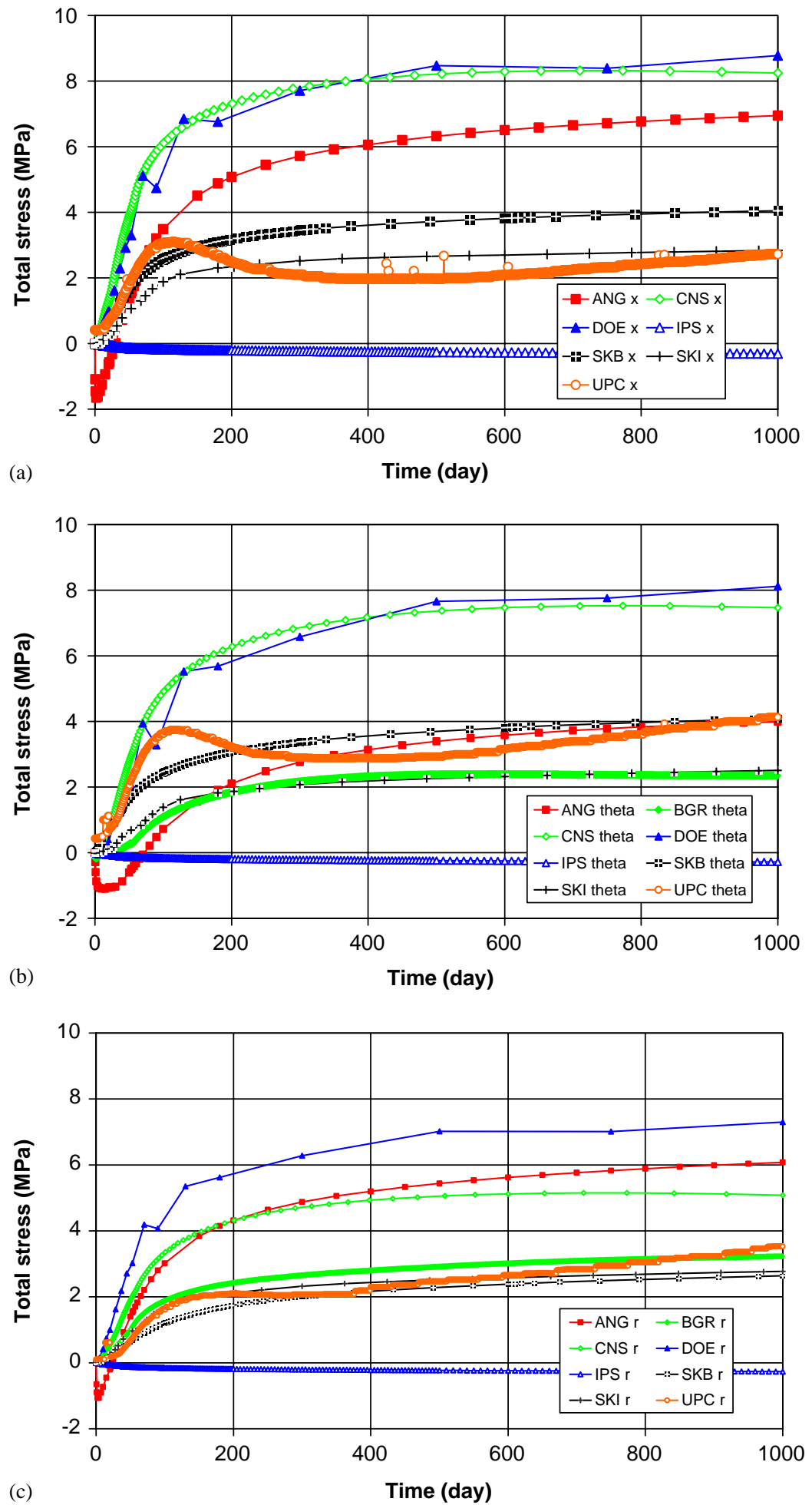

Fig. 27. Evolution of normal stresses $\left(\sigma_{x}, \sigma_{\theta}, \sigma_{\mathrm{r}}\right)$, recorded in boring SG2 and predictions of four research teams.

radial distances of $2.59,2.97$ and $3.25 \mathrm{~m}$, respectively. Recorded values at a larger radial distance $(r=7.10-7.80 \mathrm{~m})$, not shown here, were significantly lower. Interestingly, a peak is recorded at early stages in all the three stress components, followed by a transient decay and a progressive increase at later dates. The stress cells measure total stress and the observed behavior is consistent with the expected change in pore water 


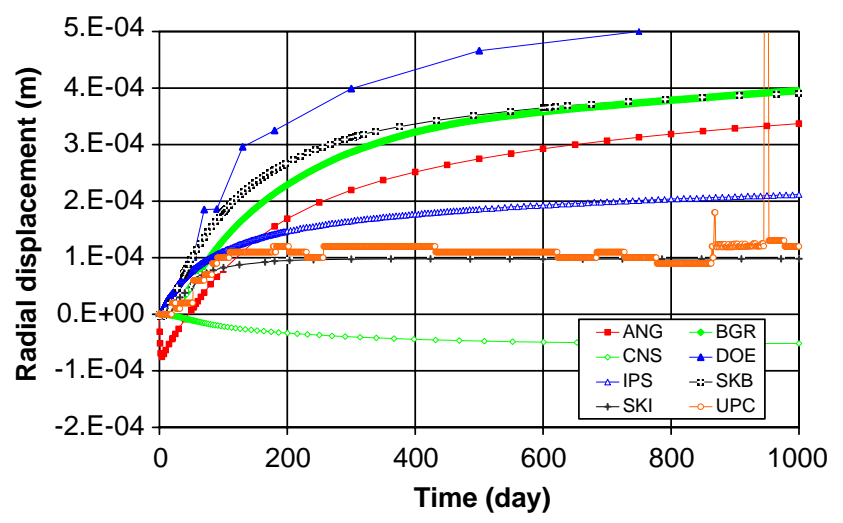

Fig. 28. Evolution of radial displacements recorded in boring SI1, extensometer fixed at a radial distance of $8 \mathrm{~m}$ and predictions of research teams.

Table 10

Modelling approaches used for Part C

\begin{tabular}{llllll}
\hline Team & Couplings & $\begin{array}{l}\text { Heat } \\
\text { flow }\end{array}$ & $\begin{array}{l}\text { Rock th. } \\
\text { dil. }\end{array}$ & $\begin{array}{l}\text { Wat. } \\
\text { th. dil. }\end{array}$ & $\begin{array}{l}\text { Wat. } \\
\text { flow }\end{array}$ \\
\hline ANG & - & - & - & - & - \\
BGR & TH $\rightarrow$ TM, & $\bullet$ & $\bullet$ & & $\bullet$ \\
& TH) & & & & \\
CNS & THM & $\bullet$ & $\bullet$ & $\bullet$ & $\bullet$ \\
DOE & TH $\rightarrow$ TM & $\bullet$ & $\bullet$ & $\bullet$ & $\bullet$ \\
IPS & THM & $\bullet$ & $\bullet$ & $\bullet$ & $\bullet$ \\
JNC & TH & $\bullet$ & & $\bullet$ & $\bullet$ \\
SKB & THM & $\bullet$ & $\bullet$ & $\bullet$ & $\bullet$ \\
SKI & THM & $\bullet$ & $\bullet$ & $\bullet$ & $\bullet$ \\
\hline
\end{tabular}

pressures, explained before. The stress predictions shown in the figures do not reproduce the measured transient, however. Some of the calculated values (especially for SKI) are quite close to actual absolute values.

Radial displacements measured in one of the extensometer rods installed are shown in Fig. 28. The extensometers measure the relative motion of the anchoring point with respect to the tunnel wall. The data in Fig. 28 refers to a $4 \mathrm{~m}$ long bar. Measured displacements (away from the tunnel wall) are very small, in the order of $0.1 \mathrm{~mm}$. They increase rapidly at early stages due to the stressing and dilation of the rock and remain essentially constant for the rest of the measuring period (despite the increasing swelling pressure). Some of the predictions are quite accurate (IPS, SKI). Some uncertainties remain, however, because the measured values are close to the precision of the measuring system.

\section{Discussion-Part C}

Temperature distributions are well reproduced in general terms. In fact, some of the calculations are very precise, unlike the case of temperature prediction for the buffer. In the case of the (saturated) rock heat flow is essentially controlled by constant parameters: the granite heat conduction and heat capacity coefficients. Convective heat transport is very small because of the negligible flow rate towards the bentonite. In the bentonite buffer, besides the effect of degree of saturation on conductivity and specific heat, other phenomena are at play: the heat transport associated with convective and diffusive flows of liquid water and vapour. This situation may explain the different performance of models in both cases.

Rock water pressures development integrates several separate phenomena: the modification of the hydrogeological regime in the vicinity of the tunnel due to the presence of the barrier, temperature effects and the influence of the suction of the bentonite.

Due to the different dilation properties of the pore water and the rock skeleton, a transient increase in temperature in a saturated porous medium induces a transient increase in pore water pressure. The magnitude of the increment of pore water pressure increases with the rate of temperature increase, the porosity and the rock stiffness. The rate of dissipation of the excess of pore water pressure increases with the rock permeability. As no clear transients of pore water pressure were recorded, this indicates comparatively high values of the rock permeability in the measuring zones. This view is supported by the observed evolution of the pressure of the water used to inflate the packers dividing the instrumented boreholes into intervals, exhibiting essentially an undrained behaviour.

Some of the phenomena controlling the evolution of pore water pressures in the rock go in opposite directions. For instance, if temperature-induced pore water pressure development is a dominant phenomenon, points closer to the experiment axis should be expected to develop higher pore water pressures than points deeper in the rock, because the former will experience a larger temperature increase. On the other hand, if the natural gradient-induced flow dominates, points located at increasing radial distances will tend to show higher pore water pressures. Bentonite suction will tend to enhance this second effect and may even induce negative pore pressures in the granite under certain circumstances. In fact, the interaction between granite and buffer in the proximity of the interface is not a straightforward phenomenon. Important qualitative differences in behaviour may be explained by relatively minor changes of the bentonite and granite constitutive parameters. A sensitivity analysis of the behaviour of this interface is given in [19].

The measured pressure response at $r=13.06 \mathrm{~m}$ in boring SF21 (Fig. 26) is unfortunately not conclusive because of the abnormal fall of pressure recorded during a relatively long period $(t=80-480$ days $)$. Some 
transient increases recorded during this period and the readings during the second half of the considered period tend to show that the actual water pressure in the rock at the sensor position increases steadily from an initial value of $0.75 \mathrm{MPa}$ to final values close to $0.9 \mathrm{MPa}$. This is a pressure higher than the recorded value at $r=$ $3.03 \mathrm{~m}(0.3-0.7 \mathrm{MPa})$. No transient changes of pressure were recorded in this transducer, which is close to the bentonite-rock interface. This data is interpreted as an indication that the distribution of pore water pressure in the rock is mainly controlled by a pure radial flow induced by hydraulic gradients. No indication of negative (or, indeed, a transient decrease in pore pressure) was detected in the granite. The interpretation is that the suction of the bentonite had in this case a negligible effect. This is also a consequence of the relatively high value of the granite matrix permeability and the small flow rates required to progressively hydrate the bentonite.

Some results favour this interpretation (SKI, JNC and SKB - although it calculated some initial negative values of water pressure in the proximity of the bentonite interface-). In an extreme position is the case of ANG, who predicted very dominant suction-induced effects. In general, none of the modelling teams predicted temperature-related water pressure effects, a fact which is explained by the rock permeability, already calibrated during the first part of the benchmark exercise.

The recorded total stresses have two components: effective stress and water pressure. Measured stresses correspond to changes experienced after cell installation, once the FEBEX tunnel was excavated. They measured total stress increments induced by temperature changes and, to a lesser extent, by the swelling of the bentonite. The most distinctive feature of the stress records is the peak values recorded in all three values of stress $\left(\sigma_{\mathrm{r}}, \sigma_{\theta}, \sigma_{x}\right)$ measured in borehole SG2 at an early stage (100 days). The fact that the stresses decreased later in the period $t=100$ days to $t=400$ days, to increase slowly at increasing times, suggests that the stress cells measured a transient change in pore water pressure induced by the increase in temperature. The subsequent reduction of total stress reflects the dissipation of excess pore water pressure. This behaviour also indicates that the system used to measure pore water pressures (isolated stretches of boreholes by means of packers) is not suitable to record point values. The measured pressure in a borehole interval is the average of "point" pressures along the measuring interval. In addition, any highly conductive feature crossing a measuring borehole interval would reduce fast any temperature-induced increase in pressure. On the other hand, the stress cells tend to provide point measurements and they are better suited to detect local changes.
None of the models predicted the recorded peak of total stress. This is, of course, consistent with the calculated pore water pressures, discussed previously. Some of the teams (CNS, ANG, and DOE) overestimated the measured stresses. Others (SKI, SKB, and BGR) reported values closer to actual data (2-4 MPa at early times and 3-4 MPa at the end of the measuring period).

An approximate calculation of the evolution of effective mean stress and the octahedral shear stress in borehole "SG" at a radial distance $r=3 \mathrm{~m}$ has been made on the basis of field observations. Pore pressures were approximated by data collected in neighbouring boreholes. It was also assumed that normal stresses on the three normal planes are principal stresses. The results are given in Table 11.

At a radial distance of $3 \mathrm{~m}$, the increments of mean effective stress dominate. Incremental shear stresses tend to be a fraction of the incremental mean stresses. The maximum difference of effective mean stresses is slightly higher, as shown also in the same table. Given the expected strength properties of the granite, the effective stress path corresponding to these values separates from the failure envelope. It is also interesting to note that the worst condition (in terms of proximity to a failure envelope) is met when octahedral stresses reach a peak (at $t=100$ days approximately). At later times, mean effective stresses dominate.

Measured displacements are a consequence of the temperature increase, which controls also the changes in effective stress. In view of the high granite stiffness the recorded displacements between an anchored point within the boring SI-1 at a radial distance of $8.03 \mathrm{~m}$ and the tunnel wall is very small $(0.1 \mathrm{~mm})$ and close to the precision of the measuring system. Most of the teams overestimated this value but SKI reported a very good prediction.

The experience gained in the simulation of rock behaviour for part $\mathrm{C}$ of the benchmark, indicates that some simplifications lead to good results. The rock permeability may be assumed to be homogeneous. In fact, due to the comparatively high rock permeability, the characteristic time of heating was larger than the characteristic time of relaxation of pore water pressure.

Table 11

Evolutions of increments of mean effective stress $\Delta p^{\prime}$, octahedral shear stress $\Delta \tau_{\text {oct }}$ and maximum shear stress $\Delta \tau_{\max }$ in Borehole SG2 at $r \approx$ $3.0 \mathrm{~m}$

\begin{tabular}{rlll}
\hline Time (day) & $\Delta \mathrm{p}^{\prime}(\mathrm{MPa})$ & $\Delta \tau_{\text {oct }}(\mathrm{MPa})$ & $\Delta \tau_{\max }(\mathrm{MPa})$ \\
\hline 0 & 0.00 & 0.00 & 0.00 \\
100 & 2.56 & 0.82 & 1.00 \\
300 & 1.96 & 0.37 & 0.40 \\
700 & 2.26 & 0.53 & 0.65 \\
1000 & 2.80 & 0.53 & 0.65 \\
\hline
\end{tabular}


Consequently, the heterogeneous nature of the rock hydraulic conductivity features may be disregarded. It was also recognized a negligible mechanical influence of the bentonite buffer. Stress increments due to the swelling of the bentonite buffer are small when compared to the stress increments due to the heating action of the buffer on the rock. On the other hand, due to the relatively high stiffness of the host rock, the induced displacements are relatively small. Therefore, for most practical purposes, a simplified constitutive model could be used for the bentonite and, in particular, for its swelling behaviour.

\section{Conclusions}

The FEBEX test is one of the few large-scale tests available to gain an integrated perspective of the behaviour of current concepts for nuclear waste disposal in crystalline rock. The comprehensive instrumentation installed in the rock and in the compacted bentonite buffer has yielded vast amounts of data over the past 6 years. Part of this data, the data corresponding to the first 3 years of heating, has been used to conduct a Benchmark exercise to evaluate the capabilities of a number of finite element codes developed to handle coupled problems in geological and porous media. This paper provides an account of the main results achieved during the performance of the exercise. Some selection of the large amount of results has been unavoidable. A description of the hypotheses and specific features of the different codes participating is also outside the scope of this paper. However, a few companion papers provide a detailed insight into some of the models and computer tools participating in the Benchmark.

For the purposes of the organization of the exercise into specific tasks the Benchmark was divided into three main parts: A: Rock behaviour during the excavation of the FEBEX tunnel; B: Buffer behaviour and C: Rock behaviour during the heating and (partial) hydration of the buffer. This distribution has been maintained in the paper.

A discussion for each of the mentioned parts has been given before. Only a few concluding points will be added here:

The best predictions of the water inflow into the excavated tunnel are found when the hydro-geological model is properly calibrated on the basis of other known flow measurements in the same area. The particular idealization of the rock mass (equivalent porous media, discrete fractures) plays a secondary role.

The development and dissipation of excess pore water pressures in the vicinity of the advancing tunnel (at the time of the FEBEX tunnel excavation) was a clear example of hydro-mechanical interaction. It was concluded that the development of pore pressures was controlled by the initial stress field state, by the rate of excavation and by the permeability and drainage properties of the granite. However, the available information on the intensity and direction of principal stresses in the area was found inconsistent with the actual measurements. The problem posed by this discrepancy was essentially unsettled since a precise determination of the initial stress state in the vicinity of the FEBEX tunnel was not available.

Predicting the behaviour of the buffer under the combined heating and wetting actions requires a fully coupled THM formulation, which incorporates all the necessary physical processes controlling the bentonite behaviour. Only a partial set of codes could offer the required features. Particularly relevant to predict the early stages of heating was the inclusion of phase changes of water and of water vapour transport. Codes incorporating these features were capable of making good predictions. It should be added that the FEBEX "in situ" test benefits from a comprehensive experimental information on compacted bentonite properties derived from a large variety of laboratory tests on samples and on small-scale hydration and heating cells.

It has been shown that the hydration of the bentonite buffer was essentially independent of the heterogeneous nature of the rock hydraulic conductivity features. This is explained by the fact that the rock matrix permeability is higher than the saturated bentonite permeability. Some 3D analyses performed, where the heterogeneous permeability features of the rock have been included, tend to support also this conclusion.

The heating of the rock resulted in a significant increase in rock stresses in the vicinity of the FEBEX tunnel. Water pressures remained however essentially unchanged. The relatively high rock permeability explains the absence of significant pore water pressure transients as a result of the rate of imposed temperature change. Only one of the participating modelling teams was capable of achieving a consistent prediction of all the measured variables in the rock: temperature, water pressures, rock stresses and radial displacements.

\section{Acknowledgements}

The authors wish to acknowledge and thank the support provided by the Research Project DECOVALEX III during the development of the work partially reported in this paper. Discussions with all the modelling teams participating in the benchmark exercise have been very useful to increase the level of understanding of the observed behaviour of the FEBEX "in situ" test. A particular appreciation is extended to ENRESA, the Spanish National Agency for Nuclear Waste Disposal, owner and manager of the FEBEX test, for his permission to release the data for the purposes of the benchmark test and for his support 
during the test operation and analysis. The European Community has economically supported the research activities in FEBEX by means of Projects funded within the 4th and 5th Research Framework Programs.

\section{References}

[1] Keusen HR, Ganguin J, Schuler P, Buletti M. Grimsel test site. Geology. NAGRA, NTB 87-14E, 1989.

[2] Pardillo J, Campos R, Guimerà J. Caracterización geológica de la zona de ensayo FEBEX (Grimsel-Suiza). CIEMAT, 70-IMA-M2-01, 1997.

[3] Guimerà J, Ortuño F, Vázquez E, Ruiz B, Martínez L, Carrera J, Meier P. Pulse tests at "in drift" boreholes. Performance and evaluation. UPC, 70-UPC-L-0-1001, 1996.

[4] Guimerà J, Carrera J, Martínez L, Vázquez E, Ortuño F, Fierz T, Bülher C, Vives L, Meier P, Medina A, Saaltink M, Ruiz B, Pardillo J. FEBEX Hydrological characterization and modeling, UPC. 70-UPC-M-0-1001, 1998.

[5] Amiguet, JL. Grimsel test site. Felskennwerte von intaktem Granit. Zusammen-stellung felsmechanischer Laborresultate diverser granitischer Gesteine. NAGRA, NIB 85-08, September 1985.

[6] Bräuer V, Kilger B, Pahl A. Grimsel test site. Engineering geological investigations for the interpretation of rock stress measurements and fracture flow tests. NAGRA, NTB 88-37E, April 1989.

[7] Pahl A, Heusermann St, Bräuer V, Glöggler W. Grimsel test site. Rock stress investigations. NAGRA, NTB 88-39E, 1989.

[8] Finsterle S, Pruess K. Solving the estimation-identification problem in two-phase flow modeling. Water Resour Res 1995;31(4):913-24.

[9] Villar MV. Thermo-hydro-mechanical characterization of a bentonite from Cabo de Gata. A study applied to the use of bentonite sealing material in high level radioactive waste repositories. Ph.D. Dissertation and ENRESA Technical Publication 01/2002, Madrid. 2002.

[10] Villar MV, Lloret A. Variation of the intrinsic permeability of expansive clays upon saturation: measurement with gas and water. In: K. Adachi, M. Fukue, editors. Clay science for engineering. Proceedings of the International Symposium on Suction, Swelling, Permeability and Structure of Clays, Shizuoka, Japan, 11-13 January. Balkema, 2001. p. 259-66.

[11] Villar MV, Lloret A. Temperature influence on the hydromechanical behavior of a compacted bentonite. In: Proceedings of the international meeting on clays in natural and engineered barriers for radioactive waste confinement, Reims, 2002.

[12] Villar MV, Lloret A. Temperature influence on mechanical behavior of a compacted bentonite. In: Proceedings of the GEPROC. International conference on coupled THMC processes in geosystems, 2003.

[13] Villar MV, Martín PL, Lloret A, Romero E. Second report on thermo-hydro-mechanical laboratory tests. CIMNE-CIEMAT Report no 70-IMA-L-0-97, 2002.

[14] Huertas F, Fuentes-Cantillana JL, Jullien F, Rivas P, Linares $\mathrm{J}$, Fariña $\mathrm{P}$, Ghoreychi M, Jockwer N, Kickmaier W, Martinet MA, Samper J, Alonso E, Elorza FS. Full scale engineered barriers experiment for a high-level radioactive waste in crystalline host rock (FEBEX Project). Final Report. European Commission. Report no EUR 19147 EN, 2000

[15] Romero E, Villar MV, Lloret A. Thermo-hydro-mechanical behavior of two heavily overconsolidated clays. In: Sixth international workshop on key issues in waste isolation research, Barcelona, 2001

[16] Pintado X, Ledesma A, Lloret A. Backanalysis of thermohydraulic bentonite properties from laboratory tests. Engineering Geology 2002;64:91-115.

[17] Lloret A, Villar MV, Sánchez M, Gens A, Pintado X, Alonso EE. Mechanical behavior of heavily compacted bentonite under high suction changes. Géotechnique 2003;53(1): $27-40$.

[18] Gens, A., The role of Geotechnical Engineering for nuclear energy utilization. In: Vaniček et al., editors. Proceedings of the XIII ECSMGE (25-28.08.2003, Prague), Special Lecture 2, vol. 3, Prague, 2003. p. 25-67.

[19] Gens A, Guimaraes LN, García-Molina AJ, Alonso EE. Interaction between clay barrier and host medium in radioactive waste isolation. Environmental Geotechnics Balkema $1998 ; 1: 581-8$. 